\title{
Comparison of spatial association approaches for landscape mapping of soil organic carbon stocks
}

\author{
B. A. Miller, S. Koszinski, M. Wehrhan, and M. Sommer \\ Leibniz Centre for Agricultural Landscape Research (ZALF) e.V., Institute of Soil Landscape Research, \\ Eberswalder Straße 84, 15374 Müncheberg, Germany \\ Correspondence to: B. A. Miller (miller@zalf.de)
}

Received: 14 October 2014 - Published in SOIL Discuss.: 5 November 2014

Revised: - - Accepted: 17 February 2015 - Published: 4 March 2015

\begin{abstract}
The distribution of soil organic carbon (SOC) can be variable at small analysis scales, but consideration of its role in regional and global issues demands the mapping of large extents. There are many different strategies for mapping SOC, among which is to model the variables needed to calculate the SOC stock indirectly or to model the SOC stock directly. The purpose of this research is to compare direct and indirect approaches to mapping SOC stocks from rule-based, multiple linear regression models applied at the landscape scale via spatial association. The final products for both strategies are high-resolution maps of SOC stocks $\left(\mathrm{kg} \mathrm{m}^{-2}\right)$, covering an area of $122 \mathrm{~km}^{2}$, with accompanying maps of estimated error. For the direct modelling approach, the estimated error map was based on the internal error estimations from the model rules. For the indirect approach, the estimated error map was produced by spatially combining the error estimates of component models via standard error propagation equations. We compared these two strategies for mapping SOC stocks on the basis of the qualities of the resulting maps as well as the magnitude and distribution of the estimated error. The direct approach produced a map with less spatial variation than the map produced by the indirect approach. The increased spatial variation represented by the indirect approach improved $R^{2}$ values for the topsoil and subsoil stocks. Although the indirect approach had a lower mean estimated error for the topsoil stock, the mean estimated error for the total SOC stock (topsoil + subsoil) was lower for the direct approach. For these reasons, we recommend the direct approach to modelling SOC stocks be considered a more conservative estimate of the SOC stocks' spatial distribution.
\end{abstract}

\section{Introduction}

The storage of carbon in soil is a critical point of information for several environmental issues. Globally, soil carbon, which is about $60 \%$ organic carbon, accounts for 3.3 times more carbon than that found in the atmosphere (Lal, 2004). The high amount of carbon stored in the soil makes soil carbon an important factor for understanding the carbon cycle and dynamics influencing global climate change (Grace, 2004; Johnston et al., 2004; Powlson et al., 2011). In addition, higher concentrations of soil organic carbon (SOC) are associated with better water storage capacity, regulation of nutrients, and stabilization of soil aggregates, resulting in improved soil structure and resistance to erosion (Neemann, 1991; Angers and Carter, 1996; Rawls et al., 2003; Snyder and Vazquez, 2005; Johnston et al., 2009; Kay, 1998; Wilhelm et al., 2004). Each of these factors has important roles in issues of water management and crop productivity.

Although SOC management has far-reaching implications, the distribution of SOC is highly variable and dynamic at the field scale (Cambardella et al., 1994; McBratney and Pringle, 1999; Walter et al., 2003; Kravchenko et al., 2006b; Simbahan et al., 2006). Differing conditions, such as hydrology or management practices, greatly impact the SOC content (Kravchenko et al., 2006a). The combination of global implications and high spatial variability make high-resolution maps of SOC for large extents desirable for both policy decisions and land-owner response. This situation creates the need to accurately and efficiently assess the spatial distribution of SOC stocks at a high resolution. High-resolution 
mapping captures information essential for assessing fieldspecific conditions, which can later be aggregated as needed to provide summary information.

Many studies have tested a variety of strategies for predicting the spatial distribution of SOC (Minasny et al., 2013, and references therein). The various studies on SOC mapping have analysed different soil depths, which has large implications for the consideration of the complete SOC stock (Richter and Markewitz, 1995; Batjes, 1996; Jobbágy and Jackson, 2000; Sombroek et al., 2000; Schwartz and Namri, 2002; Meersmans et al., 2009). For example, some have focused on spatially modelling the topsoil to depths of 20$30 \mathrm{~cm}$ (e.g. Ungaro et al., 2010; Zhang et al., 2010; Martin et al., 2011). Other variations in strategies for digital SOC mapping differ in which variables are modelled in order to predict SOC. For instance, some studies have modelled the SOC stock (e.g. $\mathrm{kg} \mathrm{m}^{-2}, \mathrm{~T} \mathrm{ha}^{-1}, \mathrm{~kg} \mathrm{~m}^{-3}$ ) directly (Simbahan et al., 2006; Lufafa et al., 2008; Nyssen et al., 2008; Mishra et al., 2010; Phachomphon et al., 2010; Kempen et al., 2011), while others have separately modelled the variables needed to calculate the SOC stock and then combined them (Grimm et al., 2008; Khalil et al., 2013; Lacoste et al., 2014). The usual component variables are total bulk density (BD), particles $>2 \mathrm{~mm}$ (SK), SOC concentration (SOC\%), and stock thickness $(H)$, which are then combined by

$\mathrm{SOC}_{\text {stock }}=\left(\frac{\mathrm{SOC} \%}{100}\right) \cdot(\mathrm{BD} \cdot 1000) \cdot\left(\frac{100-\mathrm{SK}}{100}\right) \cdot H$,

where $\mathrm{SOC}_{\text {stock }}$ is in $\mathrm{kg} \mathrm{m}^{-2}, \mathrm{SOC}_{\%}$ is in percent, $\mathrm{BD}$ in $\mathrm{g} \mathrm{cm}^{-3}$, SK in percent, and $H$ in $\mathrm{m}$.

Irrespective of the approach used, an important output of digital soil mapping is a measure of uncertainty. Orton et al. (2014) compared uncertainties resulting from directly modelling the SOC stock (direct: calculate then model) with modelling component variables for calculating the SOC stock (indirect: model then calculate), based on geostatistical approaches that rely on spatial autocorrelation. In the present study, we made a similar assessment for rule-based, multiple linear regression (MLR) models, which rely on spatial association.

With the spatial association (i.e. spatial regression) approach to soil mapping, the empirical model error can be transferred along with the model itself (Lemercier et al., 2012). For digital soil mapping, Malone et al. (2011) adapted the Shrestha and Solomatine (2006) approach for empirically summarizing model error and extending that information to prediction areas. In those previous studies, areas expected to have similar errors were grouped by cluster analysis. Because similar sites are already grouped together in rule-based, MLR models, the estimated errors can be applied to the areas meeting the same rule conditions and thus mapped. The ability to map predictions of soil properties and the confidence in those predictions via spatial association is important for landscape to national extents because of the common limitation of sampling density (Martin et al., 2014).
The purpose of this study was to compare the maps of SOC stocks produced from direct and indirect modelling approaches, using rule-based MLR. The resulting maps were compared in terms of their predicted spatial patterns, coefficient of determination $\left(R^{2}\right)$, and the magnitude and spatial distribution of the estimated errors. The predictors selected for the models via the data mining procedure were evaluated in the context of known landscape processes. In addition, the separate assessment of topsoil and subsoil stocks tested the models' ability to predict SOC storage at depths to $2 \mathrm{~m}$.

\section{Methods}

\subsection{Study area and sampling}

A dominantly agricultural area located near Wulfen, SaxonyAnhalt, Germany, which has been examined by several previous studies (Selige et al., 2006; Brenning et al., 2008; Kühn et al., 2009; Migdall et al., 2009), was selected for this research. The mapping area extends from $11.86^{\circ} \mathrm{E}, 51.74^{\circ} \mathrm{N}$ to $11.96^{\circ} \mathrm{E}, 51.90^{\circ} \mathrm{N}$ (Fig. 1), covering a total area of $122 \mathrm{~km}^{2}$. The landscape includes hummocky till plain, outwash plain, loess, and a broad floodplain (Königlich Preußische Geologische Landesanstalt, 1913a, b). The study area is dominated by Calcaric Cambisols and Luvic Phaeozems, while the depressional area in the floodplain is primarily Dystric Gleysols (European Commission, 2014). Between 2005 and 2006, 117 locations were sampled from a variety of landscape positions in 12 different agricultural fields, covering the known feature space for agricultural land in this area. Because all models were calibrated and validated on these samples, evaluation of the resulting maps focused on areas with similar land use (i.e. water bodies and urban areas excluded). Ten of the sample points, also spread across the feature space, were of repeated locations (within $2 \mathrm{~m}$ of original), which helped to insure that random error was reflected in the assessment of estimated error.

Soil horizons identified in the field were sampled at each sampling location. To avoid biases from horizon classifications and to focus on the two major process zones for SOC, the soil profile of $2 \mathrm{~m}$ was divided into topsoil and subsoil stocks. The division was defined by the largest decrease in SOC $\%$, as determined by lab analysis, between field identified horizons. Not all profiles were able to be sampled to the full depth of $2 \mathrm{~m}$. In those cases, the properties of the sampled subsoil were assumed to be representative of the remaining depth. Data for the horizons within each stock were combined using a thickness-weighted mean, as appropriate. Descriptive statistics for these observation points are provided in Table 1.

\subsection{Modelling}

Models for each of the target variables were generated using Cubist 2.08 software (Quinlan, 1992, 1993, 1994). Pre- 


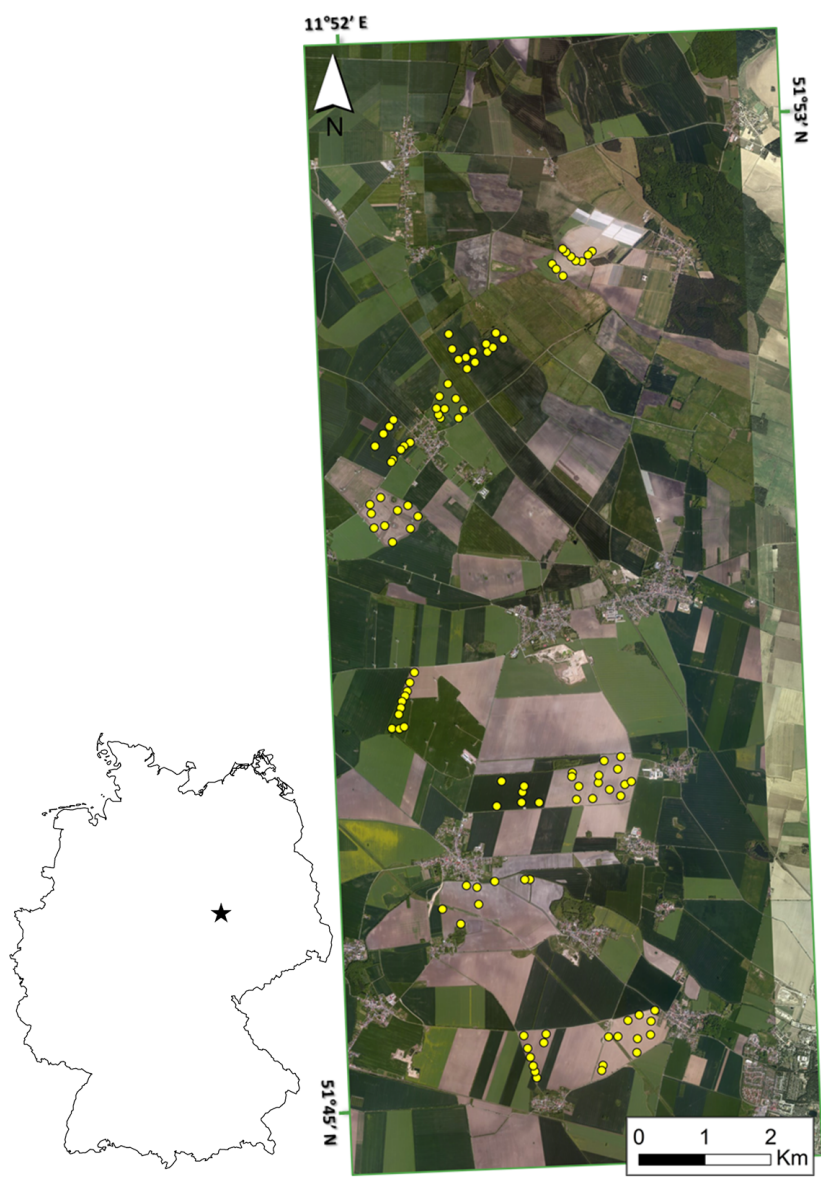

Figure 1. Locations of sample points and study area within Germany.

vious studies have demonstrated the utility of this tool for digital soil mapping (Bui et al., 2006; Minasny and McBratney, 2008; Adhikari et al., 2013; Lacoste et al., 2014). Cubist uses a data mining algorithm to build two-tiered models. The top level consists of a series of conditional rules that can utilize both continuous and categorical predictors. For each rule, a MLR equation is produced for predicting the target variable. Cubist's process for selecting predictors and building the models is described in Quinlan (1993) and Holmes et al. (1999) and will not be repeated here. One advantage of this approach is the interpretability of the produced model, which allows the modeller to assess relationships between the model and physical processes (Bui et al., 2006).

The results of the data mining process are dependent upon the predictors made available to the data mining software. For this reason, we used the large predictor pool method described by Miller et al. (2015) to identify the optimal models for each of the respective target variables. That method includes a multiple pass test, which reapplies the Cubist algorithms to the limited pool selected by the previous run. This helps to insure that the selected predictors have been optimally reduced by the Cubist software, decreasing the
Table 1. Descriptive statistics for the observed target variables. BD: total bulk density $\left(\mathrm{g} \mathrm{cm}^{-3}\right)$; SK: particles $>2 \mathrm{~mm}(\%)$; SOC $\%$ : SOC concentration $(\%) ; H$ : stock thickness $(\mathrm{cm})$; and $\mathrm{SOC}_{\text {stock }}$ : mass of organic carbon per unit area of soil $\left(\mathrm{kg} \mathrm{m}^{-2}\right)$.

\begin{tabular}{lrrrrr}
\hline Topsoil & BD & SK & $H$ & SOC $\%$ & SOC $_{\text {stock }}$ \\
\hline Min. & 1.18 & 0.00 & 10 & 0.75 & 1.80 \\
Median & 1.50 & 1.30 & 40 & 1.46 & 9.27 \\
Mean & 1.51 & 3.15 & 43.61 & 1.56 & 9.82 \\
Max. & 1.85 & 44.70 & 105 & 4.03 & 28.03 \\
SD & 0.11 & 5.50 & 15.35 & 0.53 & 4.49 \\
\hline Subsoil & & & & & \\
Min. & 1.33 & 0.00 & 18 & 0.02 & 0.07 \\
Median & 1.63 & 4.07 & 86 & 0.23 & 3.10 \\
Mean & 1.63 & 8.99 & 86.66 & 0.26 & 3.37 \\
Max. & 1.96 & 63.36 & 155 & 0.71 & 9.86 \\
SD & 0.13 & 12.28 & 32.60 & 0.13 & 2.04 \\
\hline
\end{tabular}

concern of overfitting. The predictor pool for this study included 410 base maps covering the full extent of the study area (Table 2). These base maps consisted of a legacy geologic map, a variety of remote sensing/spectral products, and digital terrain analysis (DTA). The spectral products ranged from four bands of Ikonos data to a variety of Landsat data collected at different times in 2006. DTA was conducted on a $2 \mathrm{~m}$ resolution digital elevation model (DEM), created from lidar data that were also collected in 2006. The DTA base maps included land-surface derivatives based on a wide range of analysis scales (a-scales) and a suite of hydrologic indicators. Land-surface derivatives were calculated in GRASS 6.4.3 (Geographic Resources Analysis Support System, http://grass.osgeo.org) and ArcGIS 10.1 (www.esri.com/software/arcgis). Hydrologic indicators were calculated using SAGA 2.1.0 (System for Automated Geoscientific Analysis, http://www.saga-gis.org/en/index.html).

The predictors selected by the Cubist software were then used as base maps to generate maps of $\mathrm{SOC}_{\text {stock. }}$. Using the raster calculator in ArcGIS 10.1, the base maps were combined according to the MLR equations produced by Cubist. When base maps of different resolutions were combined, the finest resolution was maintained. The respective MLR equations were only applied in the areas that met the conditions of the Cubist model's first tier. The first experimental approach used this method to directly map $\mathrm{SOC}_{\text {stock }}$ from the $\mathrm{SOC}_{\text {stock }}$ calculated at each sample point. The second experimental approach used this method to map each of the component variables. These modelled variables were then used as base maps to create a $\mathrm{SOC}_{\text {stock }}$ map. The raster calculator was then again used to combine the component variables, but this time according to Eq. (1). For both experimental approaches, the topsoil and subsoil were mapped separately. After the respective $\mathrm{SOC}_{\text {stock }}$ maps were produced, they were added together to create total $\mathrm{SOC}_{\text {stock }}$ maps. 
Table 2. Predictor variables considered in this study.

\begin{tabular}{|c|c|c|}
\hline Predictor & Software & Analysis scale \\
\hline Elevation (lidar, bare earth) & $\mathrm{n} / \mathrm{a}$ & $2 \mathrm{~m}$ \\
\hline Slope gradient & GRASS & $6-195 \mathrm{~m}$ \\
\hline Profile curvature & GRASS & $6-195 \mathrm{~m}$ \\
\hline Plan curvature & GRASS & $6-195 \mathrm{~m}$ \\
\hline Aspect - west \{rotated for N, E, and S & GRASS & $6-345 \mathrm{~m}$ \\
\hline Aspect ( 8 classes $)$ & ArcGIS (raster calculator) & $6-345 \mathrm{~m}$ \\
\hline Northness & transformed from aspect & $6-345 \mathrm{~m}$ \\
\hline Eastness & transformed from aspect & $6-345 \mathrm{~m}$ \\
\hline Longitudinal curvature & SAGA & $10 \mathrm{~m}$ \\
\hline Cross-section curvature & SAGA & $10 \mathrm{~m}$ \\
\hline Convexity & SAGA & $10 \mathrm{~m}$ \\
\hline Relative elevation - rect. neighbourhood & ArcGIS toolbox & $6-4000 \mathrm{~m}$ \\
\hline Relative elevation - circ. neighbourhood & ArcGIS toolbox & $6-4000 \mathrm{~m}$ \\
\hline Topographic position index (TPI) & ArcGIS toolbox & $6-4000 \mathrm{~m}$ \\
\hline TPI - slope position & ArcGIS toolbox & multiple \\
\hline TPI - landform classification & ArcGIS toolbox & multiple \\
\hline Hillslope position & ArcGIS toolbox & multiple \\
\hline Catchment area & SAGA & $\mathrm{n} / \mathrm{a}$ \\
\hline Catchment slope & SAGA & $\mathrm{n} / \mathrm{a}$ \\
\hline Channel network base level & SAGA & $\mathrm{n} / \mathrm{a}$ \\
\hline Convergence index & SAGA & $\mathrm{n} / \mathrm{a}$ \\
\hline Flow accumulation & SAGA & $\mathrm{n} / \mathrm{a}$ \\
\hline Flow path length & SAGA & $\mathrm{n} / \mathrm{a}$ \\
\hline Length-slope factor & SAGA & $\mathrm{n} / \mathrm{a}$ \\
\hline Modified catchment area & SAGA & $\mathrm{n} / \mathrm{a}$ \\
\hline Relative slope position & SAGA & $\mathrm{n} / \mathrm{a}$ \\
\hline SAGA wetness index & SAGA & $\mathrm{n} / \mathrm{a}$ \\
\hline Stream power & SAGA & $\mathrm{n} / \mathrm{a}$ \\
\hline Vertical distance to channel & SAGA & $\mathrm{n} / \mathrm{a}$ \\
\hline Wetness index & SAGA & $\mathrm{n} / \mathrm{a}$ \\
\hline Geology (1 : 25000 legacy map) & $\mathrm{n} / \mathrm{a}$ & 423 ha (mean) \\
\hline Predictor & Resolution & Date \\
\hline AVIS - LAI-green leaf area & $5 \mathrm{~m}$ & 21 June 2005 \\
\hline AVIS - LAI-brown leaf area & $5 \mathrm{~m}$ & 21 June 2005 \\
\hline Ikonos & $4 \mathrm{~m}, 4$ bands & 4 July 2006 \\
\hline Ikonos - panchromatic & $1 \mathrm{~m}$ & 4 July 2006 \\
\hline Ikonos - LAI & $5 \mathrm{~m}$ & 4 July 2006 \\
\hline Ikonos - dry matter & $5 \mathrm{~m}$ & 4 July 2006 \\
\hline Landsat 5 NDVI (USGS, 2014) & $30 \mathrm{~m}$ & 11 June 2006 \\
\hline Landsat 5 NDVI (USGS, 2014) & $30 \mathrm{~m}$ & 22 July 2006 \\
\hline Landsat 5 LandsatLook (USGS, 2014) & $30 \mathrm{~m}, 3+1$ band & 20 June 2006 \\
\hline Landsat 5 LandsatLook (USGS, 2014) & $30 \mathrm{~m}, 3+1$ band & 6 July 2006 \\
\hline Landsat 5 LandsatLook (USGS, 2014) & $30 \mathrm{~m}, 3+1$ band & 22 July 2006 \\
\hline Landsat 5 LandsatLook (USGS, 2014) & $30 \mathrm{~m}, 3+1$ band & 15 September 2006 \\
\hline Landsat 5 LandsatLook (USGS, 2014) & $30 \mathrm{~m}, 3+1$ band & 17 October 2006 \\
\hline Landsat 5 TM (USGS, 2014) & $30 \mathrm{~m}, 6$ bands; $60 \mathrm{~m}, 1$ band & 11 June 2006 \\
\hline Landsat 5 TM (USGS, 2014) & $30 \mathrm{~m}, 6$ bands; $60 \mathrm{~m}, 1$ band & 22 July 2006 \\
\hline Landsat 5 SR (GLCF, 2014) & $30 \mathrm{~m}, 7+2$ bands & 11 June 2006 \\
\hline Landsat 5 SR (GLCF, 2014) & $30 \mathrm{~m}, 7+2$ bands & 22 July 2006 \\
\hline
\end{tabular}


Within the extent of the study area, there were a few areas with conditions outside the range observed in the point samples. In these limited cases, extreme predictor values produced model predictions of target variables either far below or above the ranges observed for the respective target variables. To address this issue, spatial predictions were limited to be within $10 \%$ of the observed target variable's minimum and maximum.

\subsection{Propagation of error}

For each of the model rules, estimated error was calculated based on the internal fit of the MLR to the data classified within that rule. This estimation provided a measure for the respective uncertainty under each rule. The conditions for the respective rules were used to spatially classify the base maps, thus allowing the estimated errors to be mapped. Measurement error, positional error, and limitations of the model to predict the target variable were all empirically encapsulated by the estimated error.

When the target variable was the end product, the uncertainty was simply represented by the estimated error. However, when multiple variables were modelled and subsequently used to calculate the final product, the estimated errors of the component variables propagated through the combination of those variables in the function. In order to map estimated error for the indirect approach of modelling $\mathrm{SOC}_{\text {stock }}$, estimated error maps were produced for each of the component variables. These error estimation maps were then combined using standard equations for propagation of error (Mardia et al., 1979; Taylor, 1997; Weisstein, 2014). Although potentially biased by the approximation to a firstorder Taylor series expansion, simplified equations for error propagation are more practical and are regularly used in engineering and physical science applications (Goodman, $1960 ; \mathrm{Ku}, 1966)$. Because covariance between variables has the potential to impact the estimation of $\mathrm{SOC}_{\text {stock }}$ (Panda et al., 2008; Goidts et al., 2009), we did not assume the variables were independent. The observed residual covariance was thus used to modify the estimated error within the standard equations for propagation of error by multiplication,

$\sigma_{f} \approx|f| \sqrt{\left(\frac{\sigma_{A}}{A}\right)^{2}+\left(\frac{\sigma_{B}}{B}\right)^{2}+2 \frac{\operatorname{cov}_{A B}}{A B}}$,

and by addition,

$\sigma_{f} \approx \sqrt{\sigma_{A}^{2}+\sigma_{B}^{2}+2 \operatorname{cov}_{A B}}$,

where $f$ is the result of the original function (to convert from relative to estimated error), $A$ and $B$ are the real variables, with estimated errors $\sigma_{A}$ and $\sigma_{B}$, and their residuals' covariance $\operatorname{cov}_{A B}$. In order to calculate a predicted relative error (e.g. $\frac{\sigma_{A}}{A}$ ) at unsampled locations, the predicted variable was assumed to accurately represent the variable's magnitude.
Locations with small ratios between estimated error and predicted values together with large, negative covariances had the potential to produce a calculation taking the square root of a negative. This issue was addressed by not considering the covariance in those limited circumstances. While this solution may have led to an overestimation of error, it provided a means to mathematically calculate estimated error without declaring it to be zero.

\section{Results}

\subsection{Models}

\subsubsection{Model building and fitting performance}

Explicit models were obtained for each of the component variables needed to calculate $\mathrm{SOC}_{\text {stock }}$ indirectly and for predicting $\mathrm{SOC}_{\text {stock }}$ directly. Models for predicting component variables used a higher quantity of predictors for each of the respective models than the direct modelling approach (Table 3). With the exception of $\mathrm{SOC}_{\%}$, the models for component variables included a combination of DTA and spectral variables. The SOC\% models relied solely on DTA predictors for both stocks, but with additional spatial partitioning by geologic map units for the topsoil model. The models for directly predicting the $\mathrm{SOC}_{\text {stock }}$ used only three DTA predictors for the topsoil and only four Landsat predictors for the subsoil.

Fitting performances for the component variable models were better than the fitting performances for the direct modelling of $\mathrm{SOC}_{\text {stock }}$ (Table 4). For the component variables, $R^{2}$ values of subsoil models were only slightly less than the topsoil models. SOC\% was the exception by having the lowest fitting performance for the subsoil stock $\left(R^{2}=0.55\right)$, while the model for the SOC\% topsoil was able to fit observations with an $R^{2}$ of 0.86 . However, it was the aim of this research to examine whether the performance of the models was maintained through the calculation of $\mathrm{SOC}_{\text {stock }}$.

Comparison of the $\mathrm{SOC}_{\text {stock }}$ predictions by the indirect approach to observed values showed better performance for the topsoil stock $\left(R^{2}=0.73\right)$ than for the subsoil stock $\left(R^{2}=\right.$ 0.34 ). Fitting performance for directly modelling $S C_{\text {stock }}$ showed the same pattern, but was lower than the indirect approach for both stocks. Analysis of the direct approach's ability to fit observed values yielded an $R^{2}$ of 0.58 for the topsoil and 0.19 for the subsoil.

In general, calculated model efficiencies (ME) showed that the respective models reduced the mean absolute error (MAE) to about half the MAE that would result from simply using the mean of all points as the prediction. The SOC $\%$ model for the topsoil improved upon the mean model more than the other MLR models with a ME of 0.34. However, an intriguing result is the lack of model efficiency for the indirect modelling of the subsoil's $\mathrm{SOC}_{\text {stock}}$. Despite the component models all having MEs well below 1, the indirect ap- 
Table 3. Relative use (\%) of predictors in models derived by Cubist for the topsoil and subsoil stocks. BD: total bulk density ( $\mathrm{g} \mathrm{cm}^{-3}$ ); $\mathrm{SK}$ : particles $>2 \mathrm{~mm}(\%)$; SOC $\%$ : SOC concentration $(\%) ; H$ : stock thickness (cm); and $\mathrm{SOC}_{\text {stock}}$ : mass of organic carbon per unit area of soil $\left(\mathrm{kg} \mathrm{m}^{-2}\right)$.

\begin{tabular}{|c|c|c|c|c|c|}
\hline \multicolumn{3}{|r|}{ Topsoil } & \multicolumn{3}{|r|}{ Subsoil } \\
\hline Rules & MLR & Predictor & Rules & MLR & Predictor \\
\hline \multicolumn{3}{|r|}{$\mathrm{BD}$} & \multicolumn{3}{|r|}{$\mathrm{BD}$} \\
\hline $100 \%$ & $100 \%$ & Relative elev. - circ. $(2000 \mathrm{~m})$ & $100 \%$ & $0 \%$ & Geology map units \\
\hline $51 \%$ & $100 \%$ & Landsat5 SR, band 7 (6 June 2006) & $68 \%$ & $100 \%$ & LandsatLook, band 5 (6 July 2006) \\
\hline \multirow[t]{7}{*}{$17 \%$} & $100 \%$ & Relative elev. - rect. $(20 \mathrm{~m})$ & & $100 \%$ & Landsat5 NDVI (22 July 2006) \\
\hline & $96 \%$ & LandsatLook, band 5 (17 October 2006) & & $100 \%$ & LandsatLook, band 6 (6 July 2006) \\
\hline & $87 \%$ & Relative elev. - rect. $(10 \mathrm{~m})$ & & $100 \%$ & Landsat5 TM, band 1 (11 June 2006) \\
\hline & $87 \%$ & Aspect, $\mathrm{N}$ central angle $(215 \mathrm{~m})$ & & $68 \%$ & Landsat5 SR, band 7 (22 July 2006) \\
\hline & $83 \%$ & Landsat5 SR, band 2 (6 June 2006) & & $32 \%$ & Landsat5 SR, band QA (6 June 2006) \\
\hline & $34 \%$ & SAGA wetness index & & $32 \%$ & Landsat5 SR, band 1 (22 July 2006) \\
\hline & $13 \%$ & Relative elev. - circ. $(800 \mathrm{~m})$ & & $32 \%$ & Landsat5 SR, band 6 (22 July 2006) \\
\hline \multicolumn{3}{|r|}{ SK } & \multicolumn{3}{|r|}{ SK } \\
\hline $100 \%$ & $100 \%$ & TPI $(70 \mathrm{~m})$ & $100 \%$ & $3 \%$ & Stream power \\
\hline $94 \%$ & $0 \%$ & Aspect class $(70 \mathrm{~m})$ & $76 \%$ & $76 \%$ & Landsat5 SR, band 2 (11 June 2006) \\
\hline $39 \%$ & $16 \%$ & Relative elev. - rect. $(550 \mathrm{~m})$ & $21 \%$ & $0 \%$ & Profile curvature (118 m) \\
\hline \multirow[t]{10}{*}{$37 \%$} & $14 \%$ & LandsatLook, band 6 (17 October 2006) & $15 \%$ & $79 \%$ & Landsat5 SR, band 4 (6 June 2006) \\
\hline & $94 \%$ & Relative elev. - rect. (1800 m) & & $85 \%$ & Catchment slope \\
\hline & $84 \%$ & Landsat5 NDVI (11 June 2006) & & $76 \%$ & LandsatLook, band 3 (20 June 2006) \\
\hline & $80 \%$ & Aspect, $\mathrm{N}$ central angle $(50 \mathrm{~m})$ & & $56 \%$ & Landsat5 NDVI (11 June 2006) \\
\hline & $78 \%$ & Landsat5 TM, band 4 (20 June 2006) & & $56 \%$ & LandsatLook, band 4 (20 June 2006) \\
\hline & $78 \%$ & Relative elev. - circ. $(3000 \mathrm{~m})$ & & $56 \%$ & Aspect, $\mathrm{W}$ central angle $(70 \mathrm{~m})$ \\
\hline & $64 \%$ & Aspect, $\mathrm{N}$ central angle $(130 \mathrm{~m})$ & & $21 \%$ & SAGA wetness index \\
\hline & $64 \%$ & Aspect, $\mathrm{S}$ central angle $(345 \mathrm{~m})$ & & & \\
\hline & $64 \%$ & Flow path length & & & \\
\hline & $37 \%$ & Aspect, $\mathrm{N}$ central angle $(295 \mathrm{~m})$ & & & \\
\hline \multicolumn{3}{|r|}{$H$} & \multicolumn{3}{|r|}{$H$} \\
\hline $100 \%$ & $93 \%$ & Relative elev. - rect. $(1100 \mathrm{~m})$ & & & \\
\hline $39 \%$ & $100 \%$ & LandsatLook, band 5 (15 September 2006) & & & Cubist not used \\
\hline $34 \%$ & $34 \%$ & LandsatLook, band 5 (22 July 2006) & & (base & on $2 \mathrm{~m}$ - topsoil thickness) \\
\hline $25 \%$ & $93 \%$ & Ikonos, band 2 (4 July 2006) & & & \\
\hline \multirow[t]{10}{*}{$18 \%$} & $7 \%$ & LandsatLook, band 4 (17 October 2006) & & & \\
\hline & $100 \%$ & Relative elev. - rect. (1200 m) & & & \\
\hline & $93 \%$ & Ikonos, band 1 (4 July 2006) & & & \\
\hline & $93 \%$ & Relative elev. - rect. $(1300 \mathrm{~m})$ & & & \\
\hline & $74 \%$ & LandsatLook, band 4 (15 September 2006) & & & \\
\hline & $74 \%$ & TPI (1800 m) & & & \\
\hline & $74 \%$ & TPI (2600 m) & & & \\
\hline & $74 \%$ & Flow path length & & & \\
\hline & $28 \%$ & Relative elev. - circ. $(650 \mathrm{~m})$ & & & \\
\hline & $7 \%$ & Landsat5 TM, band 6 (11 June 2006) & & & \\
\hline
\end{tabular}

proach did not improve upon the mean model for predicting

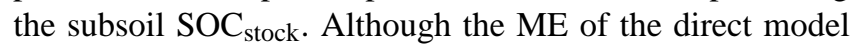
for subsoil $\mathrm{SOC}_{\text {stock }}$ was also not as good as the other models, it was still an improvement over the mean model.

\subsubsection{Model robustness}

It is common for digital soil mapping models to be evaluated by cross-validation procedures. However, in the context of this study, the meaning of such an analysis has less utility. Higher sample density increases the robustness of the model (Minasny et al., 2013); thus the popularity of cross-validation procedures over independent validation procedures in order 
Table 3. Continued.

\begin{tabular}{|c|c|c|c|c|c|}
\hline \multicolumn{3}{|r|}{ Topsoil } & \multicolumn{3}{|r|}{ Subsoil } \\
\hline Rules & MLR & Predictor & Rules & MLR & Predictor \\
\hline \multicolumn{3}{|r|}{$\mathrm{SOC}_{\%}$} & \multicolumn{3}{|r|}{$\mathrm{SOC}_{\%}$} \\
\hline $100 \%$ & $0 \%$ & Geology map units & $100 \%$ & $100 \%$ & Slope gradient (98 m) \\
\hline $49 \%$ & $39 \%$ & Relative elev. - rect. $(3200 \mathrm{~m})$ & $74 \%$ & $74 \%$ & Stream power \\
\hline $39 \%$ & $69 \%$ & Relative elev. - rect. (2000 m) & $55 \%$ & $55 \%$ & Plan curvature (138 m) \\
\hline $33 \%$ & $74 \%$ & Flow path length & & $74 \%$ & Slope gradient $(90 \mathrm{~m})$ \\
\hline \multirow{15}{*}{$21 \%$} & $62 \%$ & Northness $(155 \mathrm{~m})$ & & $74 \%$ & Slope gradient (138 m) \\
\hline & $81 \%$ & TPI (1200 m) & & $74 \%$ & Slope gradient $(185 \mathrm{~m})$ \\
\hline & $80 \%$ & Relative elev. - rect. $(250 \mathrm{~m})$ & & $74 \%$ & Relative elev. - rect. $(3400 \mathrm{~m})$ \\
\hline & $80 \%$ & Northness $(345 \mathrm{~m})$ & & $55 \%$ & Plan curvature $(90 \mathrm{~m})$ \\
\hline & $74 \%$ & Aspect, W central angle $(90 \mathrm{~m})$ & & $19 \%$ & TPI $(950 \mathrm{~m})$ \\
\hline & $69 \%$ & Relative elev. - circ. $(1600 \mathrm{~m})$ & & $19 \%$ & Vertical distance to channel \\
\hline & $69 \%$ & TPI (1100 m) & & & \\
\hline & $62 \%$ & TPI $(550 \mathrm{~m})$ & & & \\
\hline & $62 \%$ & Northness $(215 \mathrm{~m})$ & & & \\
\hline & $62 \%$ & Eastness $(345 \mathrm{~m})$ & & & \\
\hline & $62 \%$ & Modified catchment area & & & \\
\hline & $32 \%$ & Aspect, W central angle $(110 \mathrm{~m})$ & & & \\
\hline & $21 \%$ & TPI (250 m) & & & \\
\hline & $21 \%$ & Aspect, W central angle $(175 \mathrm{~m})$ & & & \\
\hline & $12 \%$ & Northness (6 m) & & & \\
\hline \multicolumn{3}{|r|}{$\mathrm{SOC}_{\text {stock }}$} & \multicolumn{3}{|r|}{$\mathrm{SOC}_{\text {stock }}$} \\
\hline $100 \%$ & $48 \%$ & Relative elev. - rect. (1100 m) & & $100 \%$ & LandsatLook, band 5 (6 July 2006) \\
\hline \multirow[t]{3}{*}{$48 \%$} & $100 \%$ & Vertical distance to channel & & $100 \%$ & LandsatLook, band 3 (6 July 2006) \\
\hline & $80 \%$ & Channel network base level & & $100 \%$ & LandsatLook, band 6 (6 July 2006) \\
\hline & & & & $100 \%$ & Landsat5 TM, band 7 (11 June 2006) \\
\hline
\end{tabular}

to maintain more points in the calibration set. However, the model generated for each cross-validation run is different because of differences in calibration sets. The performance of each run is dependent on the randomly selected calibration points' ability to represent the variation in the remaining validation points. For a simple data trend, a single outlier would have minimal effect because only the runs in which it is included in the validation set - and not used in calibrating the model - would have lower performance values. However, in a complex landscape where similar soil properties can result from different combinations of factors, the concept of an outlier has many more dimensions (Johnson et al., 1990; Phillips, 1998). A point with a similar value can be an outlier by being a product of a different set of factors. In other words, the problem of induction continues to apply in predictive soil mapping. Further, in the context of error propagation, the error estimation from the actual model used seems more appropriate than the mean of error estimations from a series of less robust models.

Nonetheless, the models in this study were cross-validated using the $k$-fold method with 10 iterations. The $R^{2}$ was naturally reduced in the cross-validation analysis, but the MAE was not as severely affected (Table 5). The $R^{2}$ val- ues for the respective models all decreased greatly in the cross-validation, except for the topsoil $\mathrm{SOC}_{\%}$ and the subsoil $\mathrm{SOC}_{\text {stock }}$ models. The subsoil $\mathrm{SOC}_{\text {stock }}$ model already had a low $R^{2}$ value for the internal fit. In contrast, the MAEs for the cross-validation of the models were not increased enough to present a practical problem. The relative stability of the MAEs also suggests that the estimated uncertainties are also robust. For example, the MAE for both stocks of BD only increased $0.03 \mathrm{~g} \mathrm{~cm}^{-3}$. Also, the MAE for SOC\% only increased 0.13 and $0.03 \%$ for the topsoil and subsoil, respectively. Similarly, the MAE for the direct $\mathrm{SOC}_{\text {stock }}$ model increased 0.67 and $0.05 \mathrm{~kg} \mathrm{~m}^{-2}$ for the topsoil and subsoil, respectively. The MAE for the models of stock $H$ and SK did increase more in cross-validation. However, they had a minor impact on the indirect modelling of $\mathrm{SOC}_{\text {stock}}$. The increase of $5.9 \mathrm{~cm}$ for the topsoil $H$ MAE was only a shift of the depth estimated by topsoil or subsoil models. The larger MAE for SK was more of an issue for the subsoil. However, the majority of the samples had SK below $5 \%$, leaving most of the error due to the difficulty in predicting the limited areas of high SK. While it was possible that a different sampling design could have improved the $R^{2}$ values for cross-validation, they are not always practical for landscape-scale mapping. 
Table 4. Fitting performance for the respective models. The model's efficiency (ME) is the ratio between the model's mean absolute error (MAE) and the MAE that would result from only using the mean value as the model. Cubist reports the $\mathrm{ME}$ as relative error, but it is renamed here to avoid confusion with the more common definition of relative error. An ME of greater than 1 indicates that the model is not performing well.

\begin{tabular}{lcccrrr}
\hline $\begin{array}{l}\text { Topsoil } \\
\text { models }\end{array}$ & BD & SK & $H$ & SOC $\%$ & $\begin{array}{r}\text { Indirect }- \\
\text { SOC }_{\text {stock }}\end{array}$ & $\begin{array}{r}\text { Direct }- \\
\text { SOC }_{\text {stock }}\end{array}$ \\
\hline MAE & 0.05 & 1.36 & 5.90 & 0.14 & 1.69 & 2.27 \\
ME & 0.52 & 0.41 & 0.47 & 0.34 & 0.49 & 0.66 \\
$R^{2}$ & 0.69 & 0.85 & 0.71 & 0.86 & 0.73 & 0.58 \\
\hline Subsoil & & & & & & \\
models & & & & & & \\
\hline MAE & 0.06 & 3.77 & 5.90 & 0.06 & 2.75 & 1.37 \\
ME & 0.58 & 0.42 & 0.47 & 0.59 & 1.67 & 0.83 \\
$R^{2}$ & 0.67 & 0.79 & 0.71 & 0.55 & 0.34 & 0.19 \\
\hline
\end{tabular}

\subsubsection{Comparison with previous studies}

It is difficult to compare results between SOC mapping studies due to differences in study areas and strategies for defining $\mathrm{SOC}_{\text {stock }}$ (i.e. map extent and resolution, sampling density, and consideration of depth). Further, the differences between and variability within methods for estimating component variables for calculating $\mathrm{SOC}_{\text {stock }}$ can have a large impact on results, especially bulk density (Liebens and VanMolle, 2003; Schrumpf et al., 2011) and SOC\% (Lowther et al., 1990; Soon and Abboud, 1991; Sutherland, 1998; Bowman et al., 2002). Also, because model performance is dependent upon the provided predictors, results of different studies can vary based on the predictors available to and derived by the modeller (Miller et al., 2015). However, because the area in this study has been used for several previous studies, some comparisons between methods can be made.

Kühn et al. (2009) examined many of the same samples used in this study and found a coefficient of determination between soil electrical conductivity and soil organic matter to a $1 \mathrm{~m}$ depth $\left(\mathrm{kg} \mathrm{m}^{-2}\right)$ of $R^{2}=0.59$. Although a slightly different calculation, that coefficient of determination is similar to this study's direct model of topsoil $\operatorname{SOC}_{\text {stock }}\left(R^{2}=0.58\right)$, which used three DTA predictors. However, for the topsoil, the indirect approach in this study produced a $\mathrm{SOC}_{\text {stock }}$ model with less estimated error and an $R^{2}$ of 0.73 . The Kühn et al. (2009) study usually included depths that this study defined as subsoil, where the models in this study did not perform as well (direct $R^{2}=0.19$, indirect $R^{2}=0.34$ ).

For the same area as this study, Selige et al. (2006) compared MLR and partial least-squares regression for predicting $\mathrm{SOC}_{\%}$ from hyperspectral data with a $6 \mathrm{~m}$ spatial resolution. Although the study by Selige et al. (2006) utilized a higher spectral resolution, the MLR models produced by both that study and the present study had an $R^{2}$ of 0.86 for
Table 5. Cross-validation performance for the respective models. Note that although the $R^{2}$ was severely reduced for most models, the MAE was generally only increased a small amount.

\begin{tabular}{lcrrrr}
\hline $\begin{array}{l}\text { Topsoil } \\
\text { models }\end{array}$ & BD & SK & $H$ & SOC $\%$ & $\begin{array}{r}\text { Direct - } \\
\text { SOC }_{\text {stock }}\end{array}$ \\
\hline MAE & 0.08 & 2.70 & 11.80 & 0.27 & 2.94 \\
ME & 0.86 & 0.82 & 0.93 & 0.66 & 0.85 \\
$R^{2}$ & 0.26 & 0.08 & 0.12 & 0.61 & 0.27 \\
\hline Subsoil & & & & & \\
models & & & & & \\
\hline MAE & 0.09 & 7.18 & 11.80 & 0.09 & 1.42 \\
ME & 0.80 & 0.80 & 0.93 & 0.98 & 0.86 \\
$R^{2}$ & 0.36 & 0.26 & 0.12 & 0.05 & 0.17 \\
\hline
\end{tabular}

the topsoil SOC\%. In the present study, Cubist was able to compensate for the limited spectral information by utilizing several DTA predictors that were available at a high spatial resolution.

\subsection{SOC $_{\text {stock }}$ maps}

Application of the obtained models and aggregation of the component variable maps by Eq. (1) produced maps of predicted $\mathrm{SOC}_{\text {stock }}$ for the topsoil and subsoil (Figs. 2 and 3). The respective topsoil and subsoil maps were added together to produce a total $\mathrm{SOC}_{\text {stock }}$ map to a depth of $2 \mathrm{~m}$ (Fig. 4). Although some field boundaries were observed, the dominant pattern appeared to be associated with terrain features. This interpretation was supported by the number of DTA predictors selected by Cubist for many of the models. However, it would not have been safe to assume this pattern from the list of selected predictors alone. Certain predictors (i.e. spectral data reflecting land use patterns) could have dominated calculations without being the most frequently selected category of predictors.

The map derived from the direct approach for modelling the topsoil SOC $_{\text {stock }}$ emphasizes drainageways. Whereas the map derived by the same approach for the subsoil SOC $_{\text {stock }}$ reflects more patterns of land use, especially in the uplands in the southern part of the study area. The topsoil SOC $_{\text {stock }}$ map based on the indirect approach has similar overall patterns to the direct approach's map. However, both the topsoil and subsoil maps produced by the indirect approach display greater spatial variation.

Patterns in the topsoil $\mathrm{SOC}_{\text {stock }}$ map, based on the indirect approach, mostly coincide with terrain features, but do contain some transitions that align with field boundaries. The corresponding map for the subsoil reflects patterns of microtopography and slope gradient. Larger values for the subsoil $\mathrm{SOC}_{\text {stock }}$ are predicted by the indirect approach for local lows in elevation (smaller a-scales). Predictions of larger subsoil $\mathrm{SOC}_{\text {stock }}$ on steeper slopes result from the modelling of thin- 

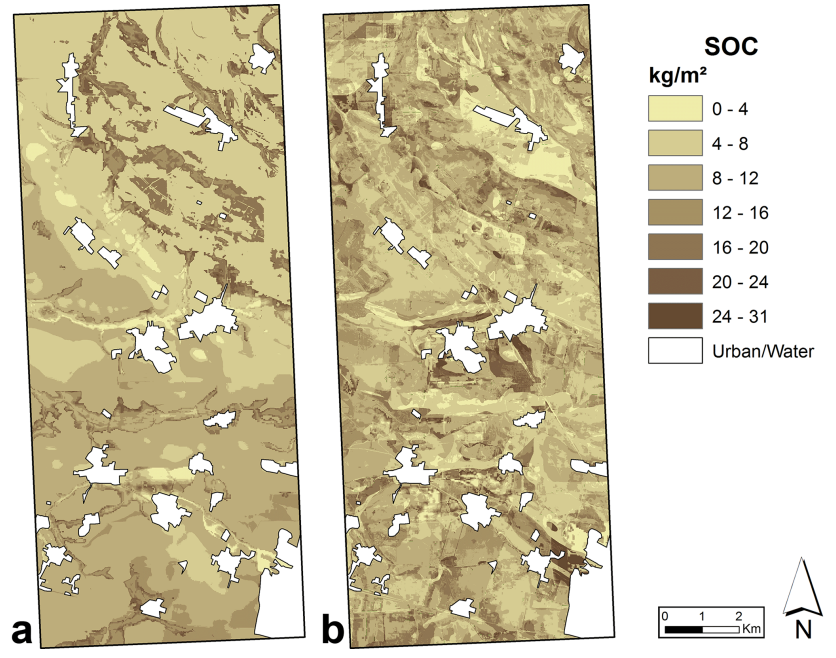

Figure 2. Topsoil $\mathrm{SOC}_{\text {stock }}$ modelled by (a) the direct approach and (b) the indirect approach. Overlaid on a hillshade to show relationship with relief and field boundaries.

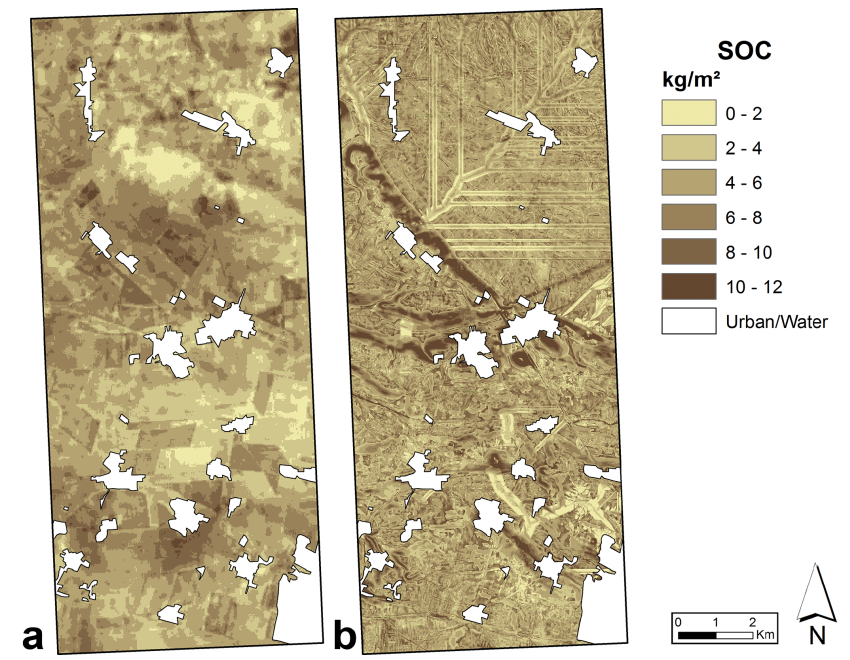

Figure 3. Subsoil $\mathrm{SOC}_{\text {stock }}$ modelled by (a) the direct approach and (b) the indirect approach. Overlaid on a hillshade to show relationship with relief and field boundaries.

ner topsoil stocks in these areas and the consistent calculation of a $2 \mathrm{~m}$ profile. Consequently, the subsoil is calculated to be thicker in these areas, substantially increasing the subsoil SOC $_{\text {stock }}$ prediction compared to other areas of the subsoil.

Maps derived by both approaches for the total $\mathrm{SOC}_{\text {stock }}$ primarily reflected patterns from the topsoil maps because of the higher concentration of SOC that defined the topsoil stock. Nonetheless, modelled storage for the subsoil stock contributed about one-third of the prediction of total $\mathrm{SOC}_{\text {stock }}$ and recognized additional complexity in the SOC landscape. Despite the greater variation in the indirect approach's prediction of $\mathrm{SOC}_{\text {stock }}$, the difference between estimates of total $\mathrm{SOC}_{\text {stock }}$ by the two approaches were within

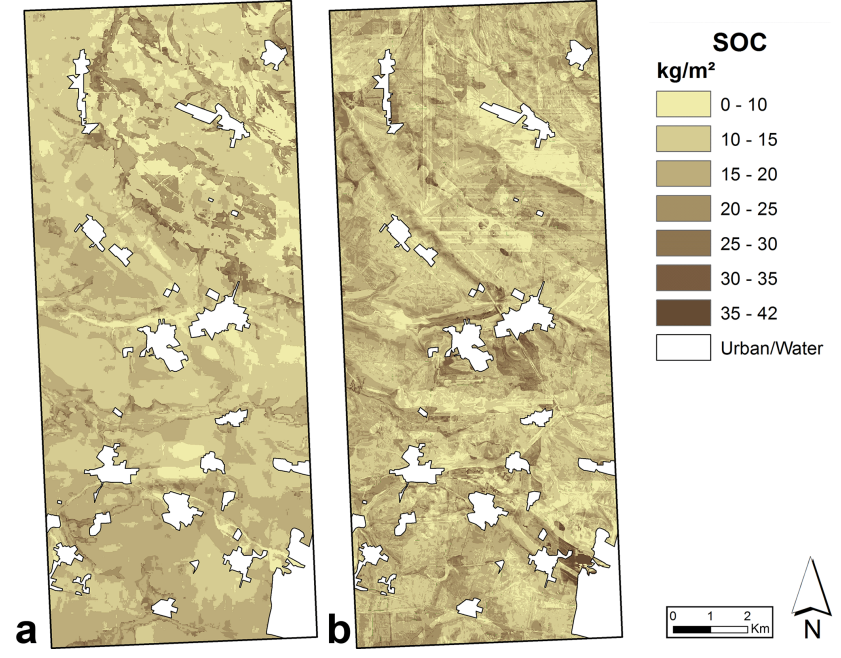

Figure 4. Total $\mathrm{SOC}_{\text {stock }}$ (topsoil + subsoil) modelled by (a) the direct approach and (b) the indirect approach. Overlaid on a hillshade to show relationship with relief and field boundaries.

$5 \mathrm{~kg} \mathrm{~m}^{-2}$ for the majority of the map area (Fig. 5). Also, the summed $\mathrm{SOC}_{\text {stock }}$ for the study area was only $6 \%$ more for the indirect $(1.9 \mathrm{Mt})$ versus the direct $(1.8 \mathrm{Mt})$ approach. The mean $\mathrm{SOC}_{\text {stock }}$ estimate for the study area by the direct approach was $14.7 \mathrm{~kg} \mathrm{~m}^{-2}$, whereas the indirect approach estimated $15.7 \mathrm{~kg} \mathrm{~m}^{-2}$.

These aggregated landscape estimates agreed with those made by the Harmonized World Soil Database (HWSD; FAO/IIASA/ISRIC/ISSCAS/JRC, 2012) for this area. The HWSD estimated several soil properties from taxonomic pedotransfer functions for static topsoil $(0-30 \mathrm{~cm})$ and subsoil $(30-100 \mathrm{~cm})$ depth zones. Within the area of the present study, the HWSD has a cell resolution of approximately $765 \mathrm{~m}$. Calculating $\mathrm{SOC}_{\text {stock }}$ from those data yielded a mean of $8.8 \mathrm{~kg} \mathrm{~m}^{-2}$. Assuming the characteristics of the subsoil to $100 \mathrm{~cm}$ extended to $200 \mathrm{~cm}$, the mean $S_{\text {stock }}$ would be $15.3 \mathrm{~kg} \mathrm{~m}^{-2}$.

\subsection{Error estimations}

The mapping of estimated errors based on the conditions of rules generated by Cubist resulted in a spatial representation of uncertainty (Fig. 6). In order to calculate the final estimated errors for the indirect approach, estimated errors for models of component variables were combined spatially using Eqs. (2) and (3). Due to the known covariance of component variables, the observed covariance of the residuals was included in the calculation of error propagation through the calculation of the total $\mathrm{SOC}_{\text {stock}}$. Inclusion of covariance reduced relative error estimates in the topsoil because increases in residuals for BD coincided with decreases in the residuals for percent fine earth, increases in fine-earth BD residuals coincided with decreases in SOC\% residuals, and increases in SOC content $\left(\mathrm{kg} \mathrm{m}^{-3}\right)$ residuals coincided with decreases 


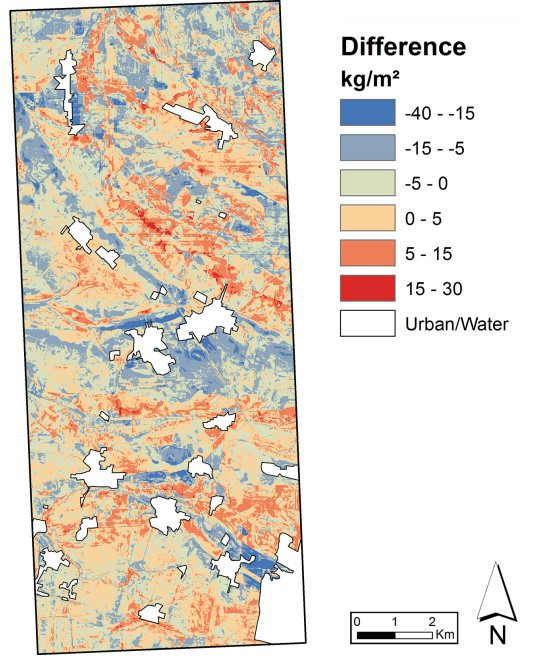

Figure 5. Calculated difference between the direct and indirect approaches of modelling the total $\mathrm{SOC}_{\text {stock}}$. Negative values are where the indirect approach predicted more $\mathrm{SOC}_{\text {stock }}$ than the direct approach and positive values are where the indirect approach predicted less.

in stock thickness residuals. The influence of covariance was mostly the same in the subsoil calculations. The exception was a positive covariance between the residuals for modelling BD and the percent fine earth. Nonetheless, the covariances were relatively small with respect to the estimated errors and therefore had a minimal impact on the final calculation of estimated error.

The application of error estimates based on the full range of predicted values in a rule zone to small values in that zone yielded extremely high relative error values. Although the areal extent for this type of situation was very limited, the issue needed to be addressed in order to maintain the readability of the attribute scale. Therefore relative error was capped at one for the original relative error grids, but not thereafter for the calculation of error propagation.

Despite not having as strong of a fitting performance as the indirect approach, the direct approach had lower estimated errors for greater extents of the study area. The mean estimated error for the total $\mathrm{SOC}_{\text {stock }}$ map derived by the direct approach was $2.81 \mathrm{~kg} \mathrm{~m}^{-2}$, compared to $8.17 \mathrm{~kg} \mathrm{~m}^{-2}$ for the indirect approach. This behaviour in the models may be explained by the negative covariance between the residuals for many of the variables influencing the $\mathrm{SOC}_{\text {stock}}$. The observed covariances did reduce the calculation of error through propagation. However, they did not reduce the estimated error for the indirect approach to as low as the estimated error based on the direct modelling approach. It is also useful to note that the residuals for modelling SK and $\mathrm{SOC}_{\%}$ had a negative and positive skew, respectively, for both stocks (Table 6). Of the residuals for the final prediction of $\mathrm{SOC}_{\text {stock}}$, regardless of approach or stock, only the indirect model for the subsoil
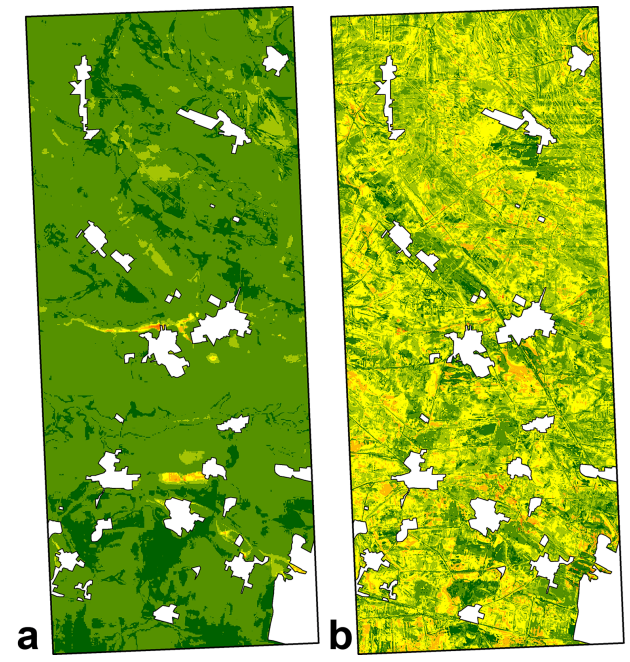

Relative Error

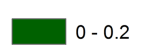

$0.2-0.4$

$0.4-0.6$

$\square .6-0.8$

$0.8-1.0$

$1.0-1.2$

$1.2-1.4$ Urban/Water

Figure 6. Estimated relative error for the total $\mathrm{SOC}_{\text {stock }}$ modelled by (a) the direct approach and (b) the indirect approach.

had strongly skewed residuals. This suggests that error for the indirect model of the subsoil SOC $_{\text {stock }}$ may have been overestimated.

The spatial distribution of model rules was an important factor in the resulting maps' estimated error. The models for the direct approach used fewer rules than the component variable models, resulting in less spatial variation in the estimated error. However, variation in predicted values did introduce additional spatial variation to the mapping of relative error. Nonetheless, the map of relative error from the indirect approach was more complex than that resulting from the direct approach. In addition to using more rules for each model, the combined relative estimated error for the indirect approach was further tessellated by the unique intersections of the different spatial distributions of the rules for each component variable model.

\section{Discussion}

\subsection{Predictor selection}

\subsubsection{Review of relationships between predictors and environmental conditions}

Spectral predictors from satellites such as Ikonos and Landsat have most commonly been used to detect characteristics of land use, vegetation, and soil water content (Bannari et al., 1995; Xie et al., 2008). However, they have also been used to detect mineralogy on sparsely vegetated areas (Mulder et al., 2011). Although Ikonos has a finer spatial resolution, it is limited to three bands (band 1: blue; band 2: green; and band 3: red) in the visible spectrum, plus a near-infrared band (band 4: NIR). Landsat provides additional bands in the shortwave infrared (band 5: SWIR-1; band 7: SWIR-2) and thermal infrared (band 6: TIR). The relative reflectance 
Table 6. Skewness coefficients for the residuals of each model.

\begin{tabular}{lrrrrrr}
\hline & BD & SK & $H$ & SOC $_{\%}$ & $\begin{array}{r}\text { Indirect - } \\
\text { SOC }_{\text {stock }}\end{array}$ & $\begin{array}{r}\text { Direct - } \\
\text { SOC }_{\text {stock }}\end{array}$ \\
\hline Topsoil models & -0.25 & -1.15 & 0.17 & 1.04 & 0.10 & 0.37 \\
Subsoil models & 0.11 & -0.74 & -0.17 & 1.18 & -1.61 & -0.16 \\
\hline
\end{tabular}

of a single band can be used to distinguish landscape conditions. For example, the green band can be used to distinguish different vegetation from bare soil. However, combinations of bands - particularly including the red and NIR bands - have been even more useful for distinguishing the spectral signature of different land uses (Richards, 2006) and the condition of the vegetation (Ashley and Rea, 1975; Myneni et al., 1995; Rasmussen, 1998; Daughtry, 2001; Hatfield et al., 2008). Additional use of TIR emission would resemble methods such as the surface temperature/vegetation index for estimating soil moisture (Bartholic et al., 1972; Heilman et al., 1976; Carlson et al., 1994; Li et al., 2009; Petropoulus et al., 2009). Similarly, use of SWIR wavelengths in concert with red and infrared bands would be a way of compensating for the changing effect of soil reflection in dry to wet conditions (Huete, 1988; Lobell and Asner, 2002). Relationships between bands in the visible to SWIR range have also been used to predict $\mathrm{SOC}_{\%}$ and its biochemical composition (Bartholomeus et al., 2008; Gomez et al., 2008; Stevens et al., 2010).

Spectral predictors have been used for both classification of discrete phenomenon and quantification of continuous phenomenon on the landscape. Because of the rule-based MLR structure of the Cubist models, spectral predictors used for conditional rules were more likely to be distinguishing discrete features (e.g. vegetation/land use type) than when used within an MLR equation. Continuous features (e.g. vegetation health) were more likely to be represented in MLR equations.

DTA predictors in this study were all derived from the lidar data for elevation. The land-surface derivatives (e.g. slope gradient, relative elevation) described the surface geometry with which the climate interacts. For example, aspect has been shown to influence the amount of solar insolation a hillslope receives (Hunckler and Schaetzl, 1997; Beaudette and O'Geen, 2009). The surface geometry is also known to direct water flow, which affects erosion processes and groundwater recharge (Huggett, 1975; Zevenbergen and Thorne, 1987). Hydrologic predictors (e.g. flow accumulation, catchment slope) provided additional information about the relative volume and energy that the water flow may have (Moore et al., 1991; Wilson and Gallant, 2000).

\subsubsection{Topsoil model predictors}

All of the topsoil models generated by Cubist relied on DTA predictors the most. Of those predictors, different a-scales of relative elevation, topographic position index (TPI), and aspect were the most commonly used. With the exception of the direct $\mathrm{SOC}_{\text {stock }}$ model, every topsoil model also included one or two predictors indicative of flow accumulation (i.e. flow path length, SAGA wetness index, or modified catchment area).

Aspect at different a-scales influenced predictions for three of the indirect topsoil models. The Cubist-generated model identified decreasing topsoil SOC $\%$ on more north facing slopes (155 m a-scale), which corresponds to a potential decrease in plant productivity due to less solar insolation. Aspect ( $215 \mathrm{~m}$ a-scale) was also used to predict higher topsoil BD on south- to west-facing slopes, especially on topographic (2000 $\mathrm{m}$ a-scale) and microtopographic (20 m ascale) highs. Additionally, aspect at a variety of a-scales was used to predict decreasing topsoil SK for low-TPI areas facing southeast to southwest. Together, these models suggested a pattern of increased erosion and deposition along the southern sides of hillslopes. This type of pattern has been observed before in other landscapes and has been attributed to topoclimatic differences such as exposure to storms, differences in temperature regime, rainfall effectiveness, or vegetation density (Kennedy, 1976; Churchill, 1981; Cuff, 1985; van Breda Weaver, 1991).

Although DTA parameters dominated the topsoil models, their predictions were often modified by spectral variables. For example, the primary distinction for predicting topsoil $H$ was between low and high relative elevations. Low relative elevations had a mean topsoil $H$ that was about $20 \mathrm{~cm}$ thicker than high relative elevations (1100 $\mathrm{m}$ a-scale). Within most MLR equations, however, predictions were increased by less blue and more green reflectance in early July. This combined use of blue and green bands indicated increasing topsoil $H$ with more productive vegetation on wetter soils. In summary, the dominant pattern identified by the model matched the pattern of high and low ground (Bushnell, 1943; Sommer et al., 2008), but the degree of topsoil thinning or thickening was predicted by the vegetation's response to soil conditions.

Cubist selected a much simpler combination of only DTA predictors to directly model the topsoil $\mathrm{SOC}_{\text {stock }}$. In general, the model predicted increasing $\mathrm{SOC}_{\text {stock }}$ with decreasing vertical distance to channel. Areas low in relative elevation (1100 $\mathrm{m}$ a-scale) and not far above the channel network were predicted to have the largest $\mathrm{SOC}_{\text {stock }}$. However, for areas low in relative elevation, but sufficiently above the 
DEM based channel network, the model predicted the opposite trend of the $\mathrm{SOC}_{\text {stock }}$ decreasing with decreasing vertical distance to channel. This pattern identified by the model may be explained by a corresponding pattern observed in the model for the topsoil $H$. In that model, areas low in relative elevation (1100 m a-scale) were predicted to have some of the thickest topsoil stocks. However, within a few of those zones the modelled topsoil $H$ decreased with decreasing relative elevation and TPI. This trend in the observed data, as detected by Cubist, was potentially caused by an eroding-out of topsoil sediments closer to the centre of drainageways, in which case, the vertical distance to channel - used in the topsoil $\mathrm{SOC}_{\text {stock }}$ model - may have been more an indicator of proximity to the channel than wetness; the threshold was only $0.5 \mathrm{~m}$ above the channel modelled from the DEM. Predictors related to surface flow energy would have been expected to be better predictors of this kind of process. However, the upslope drainage network for much of the map area extended beyond the boundaries of the available data. Thus the use of local elevation data may have been a better proxy in this case compared to the predictors calculated from truncated watersheds.

\subsubsection{Subsoil model predictors}

With the exception of $\mathrm{SOC}_{\%}$, the subsoil models all used several predictors from Landsat. Selection of Landsat predictors for subsoil models suggested that vegetation characteristics or surface soil moisture at different times of the year indicated subsoil conditions. In contrast, the subsoil SOC $\%$ model's complete dependence on DTA predictors suggested that soil property was mostly related to hydrology and that vegetation had little response to or effect on the SOC content in the subsoil.

An example of spectral predictors detecting vegetation characteristics that likely reflected subsoil conditions was the subsoil SK model. All of the MLR equations were strongly influenced by the predictors of stream power, catchment slope, or SAGA wetness index. However, the SK predictions were modified by green reflectance in June and additional Landsat predictors collected at different times of the year that related to the vigour of the vegetation. The weaker or drier the vegetation appeared, the higher the prediction of SK content in the subsoil. Assuming soil moisture conditions did not reach detrimental levels that year, these patterns fit known relationships between particle size, soil drainage, and timing to crop maturity (Day and Intalap, 1970; Rawls et al., 1982).

The generated model for subsoil BD most likely utilized a relationship with soil moisture as detected by spectral predictors. In all areas, the MLR equations decreased predictions of subsoil BD with increasing reflectance in the blue and SWIR-1 bands along with increasing emission in the TIR band. Increases in the normalized difference vegetation index (NDVI) were used to slightly increase predictions of subsoil $\mathrm{BD}$. The use of the NDVI to offset the decreasing BD pre- dicted by the other Landsat predictors suggested those variables were indicating soil moisture conditions. Locations that are wetter due to surface runoff would have a greater potential for organic material to be translocated deeper in the soil profile (Schaetzl, 1986, 1990). Also, the association of wetter environments with cooler temperatures and anaerobic conditions would also inhibit decomposition (Gates, 1942; Krause et al., 1959; Frazier and Lee, 1971).

The subsoil SOC $\%$ model was different than the other subsoil models generated. Instead of selecting spectral predictors, the subsoil SOC\% model relied solely on DTA predictors. The model predicted the highest subsoil $\mathrm{SOC}_{\%}$ on steeper mid-slopes. The pattern of increasing subsoil SOC\% from the upper to middle slope fit the landscape translocation model proposed by Sommer et al. (2000). In that study, the $\mathrm{SOC}_{\%}$ in the Bh horizon increased from the upper slope to the midslope due to lateral translocation. Different than the pattern identified in the present study, the data in Sommer et al. (2000) showed a continued increase in the SOC\% of $\mathrm{Bh}$ horizons in the downslope position. However, this contradiction may be partially explained by aggradation where the slope gradient declines and the topsoil stock has been overthickened by developmental upbuilding (McDonald and Busacca, 1988; Almond and Tonkin, 1999). Also, lateral flow would be expected to return closer to the surface at downslope positions. In Sommer et al. (2000), while the upslope and midslope profiles had $\mathrm{E}$ horizons separating the $\mathrm{Bh}$ from A horizons, the downslope Bh horizons were exceptionally thick, with little to no division between them and the A horizon. In that situation, the definition of topsoil used in the present study would have grouped the downslope Bh horizons into the topsoil stock. Therefore, the Cubist-generated model may have been a simplification of the complex interaction between topography and lateral flow depth and direction.

The rule groups for subsoil $\mathrm{SOC}_{\%}$ also differentiated for the plan curvature where the slope gradient was not too high and the stream power index (SPI) was not too low. Concave plan curvatures ( $138 \mathrm{~m}$ a-scale) were predicted to have increasingly higher and convex plan curvatures were predicted to have increasingly lower subsoil SOC\%. This relationship with plan curvature matches patterns of water movement identified to be important to soil formation by Huggett (1975), where convergent footslopes have the highest deposition rates (Pennock and De Jong, 1987). Assuming the absence of any restrictive layer below, areas with the highest sediment deposition rates would be expected to also have the highest volume of water infiltration.

The Cubist-generated model for predicting the subsoil $\mathrm{SOC}_{\text {stock }}$ was simpler than any of the indirect component models. It used only one MLR equation to relate red and infrared predictors to subsoil SOC $_{\text {stock }}$. This model predicted more $\mathrm{SOC}_{\text {stock }}$ storage with increasing reflectance in the red and SWIR-2 bands along with increasing emission in the TIR band - primarily captured on 6 July. Of 
these variables, model predictions were dominated by increasing reflectance in the red band increasing the estimated subsoil $\mathrm{SOC}_{\text {stock}}$. This suggested less productive vegetation corresponding with larger subsoil $\mathrm{SOC}_{\text {stock}}$. This trend was counter to the patterns observed in the topsoil models, but was sensible in the context of how the subsoil stock was defined for this study. Although the total $\mathrm{SOC}_{\text {stock }}$ was less in areas with lower plant productivity, the subsoil $\mathrm{SOC}_{\text {stock }}$ was larger relative to other subsoil areas due to the inverse relationship between topsoil and subsoil $H$ used in this study. A thicker topsoil stock would mean a thinner subsoil stock - and vice versa - due to the $2 \mathrm{~m}$ depth limit. Regarding the other predictors in this model, increases in SWIR-2 reflectance could have indicated more plant productivity. However, its use with the TIR band suggested that together they were indicators of wetter soil conditions.

\subsection{Unconventional predictor selections}

The Cubist software made some intriguing selections in regard to predictors that were calculated using alternative approaches. One example of this was the selection of alternative types of aspect predictors. The conversion of aspect to northness and eastness is generally considered to be the preferred method for addressing the circular problem of using aspect as a predictor. In our approach of including many different predictors in the available pool, we also experimented with simply rotating the central angle (position of $0^{\circ}$ ) to each cardinal direction for creating different aspect predictors. In the models generated for this study, northness and eastness were only selected for the topsoil SOC\% model. In contrast, rotated versions of aspect were selected for the topsoil $\mathrm{SOC}_{\%}$, topsoil BD, and the topsoil and subsoil SK models.

Another example of an intriguing predictor selection by Cubist was the use of bands from the LandsatLook products. These images were limited to four bands (SWIR-1, NIR, red, and TIR) and were smoothed by an algorithm to facilitate image selection and visual interpretation. Although the USGS does not recommend the use of these files for data analysis, the Cubist data mining found them to be more useful than the data without LandsatLook processing. Most of these selections can be explained by the greater variety of LandsatLook dates provided in the predictor pool. However, there were a few instances where Cubist chose LandsatLook data over the unprocessed version of the same Landsat data.

\subsection{Error propagation}

Although both the direct and indirect modelling approaches had base maps with a $2 \mathrm{~m}$ resolution available to them, the direct modelling approach produced a more generalized $\mathrm{SOC}_{\text {stock }}$ map. In terms of predicted error, the cost of trying to account for the variation in all of the variables related to the $\mathrm{SOC}_{\text {stock }}$ appeared to be larger relative errors. The $\mathrm{SOC}_{\text {stock }}$ model from the direct approach, on the other hand, did not attempt to predict as many variations occurring at small phenomenon scales. Because these very local variations were difficult to predict, the estimated error for the direct approach was less than for the indirect approach for most of the map area. Therefore, it may be appropriate to consider the direct modelling approach to be a conservative approach for estimating the $\mathrm{SOC}_{\text {stock }}$ for landscapes.

Possible sources of error in the base maps included atmospheric conditions for the satellite data and the estimation of bare-earth elevation under dense vegetation for the DEM. Several spectral capture dates were made available in the predictor pool to enable Cubist to not only select the optimal changes in seasonal vegetation characteristics but to also select the image with minimal noise from atmospheric effects such as clouds. Fewer options were available for DTA predictors, because all DTA predictors needed to be derived from the same high-resolution DEM. The effect of anomalies in the elevation data was more pronounced for larger a-scales. For example, a small forest plot - located roughly between the two larger cities in the centre of the map area - had not been fully filtered out by the bare-earth algorithm. Any DTA calculation that included this area in its analysis neighbourhood was incorrectly influenced by those elevation values. The impact on this study's models was an increased prediction of $\mathrm{SOC}_{\text {stock }}$ in the surrounding area.

The error propagation method used in this study could not directly account for errors in the base maps. Instead, it could only quantify the combined model, base map, and target variable error observed at sample locations. Although none of the sample points were in proximity to the before mentioned error in the DEM, this phenomenon of elevation error affecting scale-dependent predictors would have applied universally, even where the error was less obvious. The higher relative error for both mapping approaches in the area surrounding the known problem in the DEM suggested this potential source of error was at least partially accounted for.

\section{Conclusions}

This study demonstrated the use of spatial association to predict the $\mathrm{SOC}_{\text {stock }}$ and the estimated error at unsampled locations within a $122 \mathrm{~km}^{2}$ landscape at a high resolution. The Cubist data mining software detected patterns in the observed soil data, which were used to predict soil properties in the greater map region. The ability of the available base maps to predict the variation of those soil properties was quantified for each conditional rule of the respective models. The spatial characteristics of the model rules allowed the uncertainty to be mapped along with the target variable prediction.

There were two main advantages to using data mining software to produce relatively simple model structures. First, patterns between the predictors and target variables were objectively identified. Second, the resulting models were simple enough to be interpreted by the user and related to known 
processes in the soil system. A relationship between selected predictors and known processes provided confidence that their use in the model was not coincidental. The separate modelling of topsoil and subsoil stocks identified a general division between useful predictors for predicting soil properties at different depths. The data mining in this study suggested that DTA predictors tend to be most useful for topsoil properties, while spectral characteristics of vegetation and soil moisture tend to be more useful for indicating subsoil properties.

Direct and indirect approaches were tested for predicting the $\mathrm{SOC}_{\text {stock }}$ with the rule-based, MLR spatial modelling method. Although the spatial patterns in the two maps were generally similar, the indirect approach produced a map with more spatial variation. While attempting to account for more sources of variability resulted in less estimated error for the topsoil (indirect $\mathrm{MAE}=1.69$, direct $\mathrm{MAE}=2.27$ ), the indirect approach had a higher potential for error in the subsoil (indirect $\mathrm{MAE}=2.75$, direct $\mathrm{MAE}=1.37$ ). Because the direct approach accounts for less variation (topsoil: direct $R^{2}=0.58$, indirect $R^{2}=0.73$; subsoil: direct $R^{2}=0.14$, indirect $R^{2}=0.34$ ), but also results in a lower total MAE (direct $\mathrm{MAE}=3.64$, indirect $\mathrm{MAE}=4.44$ ), it should be considered a more conservative prediction of the $\mathrm{SOC}_{\text {stock }}$ 's spatial distribution. The choice of which approach is best will likely depend on a given situation's need to prioritize the representation of spatial pattern or to minimize estimated error.

Acknowledgements. Data used in this research were collected as part of the Preagro project, funded by the German Federal Ministry of Education and Research (BMBF), under grant reference number 0339740/2. We thank Carsten Hoffmann for his suggestions during the development of this study.

Edited by: B. van Wesemael

\section{References}

Adhikari, K., Kheir, R. B., Greve, M. B., and Greve, M. H.: Comparing kriging and regression approaches for mapping soil clay content in a diverse Danish landscape, Soil Sci., 178, 505-517, doi:10.1097/SS.0000000000000013, 2013.

Almond, P. C. and Tonkin, P. J.: Pedogenesis by upbuilding in an extreme leaching and weathering environment, and slow loess accretion, south Westland, New Zealand, Geoderma, 92, 1-36, doi:10.1016/S0016-7061(99)00016-6, 1999.

Angers, D. A. and Carter, M. R.: Aggregation and organic matter storage in cool, humid agricultural soils, in: Structure and Organic Matter Storage in Agricultural Soils, edited by: Carter, M. R. and Stewart, B. A., CRC Press, Boca Raton, 193-211, 1996.

Ashley, M. D. and Rea, J.: Seasonal vegetation differences from ERTS imagery, Journal of American Society of Photogrammetry, 41, 713-719, 1975.

Bannari, A., Morin, D., Bonn, F., and Huete, A. R.: A review of vegetation indices, Remote Sensing Reviews, 13, 95-120, doi:10.1080/02757259509532298, 1995.
Bartholic, J. F., Namken, L. N., and Wiegand, C. L.: Aerial thermal scanner to determine temperature of soils and of crop canopies differing in water stress, Agronomy J., 64, 603-608, 1972.

Bartholomeus, H. M., Schaepman, M. E., Kooistra, L., Stevens, A., Hoogmoed, W. B., and Spaargaren, O. S. P.: Spectral reflectance based indices for soil organic carbon quantification, Geoderma, 145, 28-36, doi:10.1016/j.geoderma.2008.01.010, 2008.

Batjes, N. H.: Total carbon and nitrogen in the soils of the world, European J. Soil Sci., 47, 151-163, doi:10.1111/j.13652389.1996.tb01386.x, 1996.

Beaudette, D. E. and O'Geen, A. T.: Quantifying the aspect affect: an application of solar radiation modeling for soil survey, Soil Sci. Soc. Am. J., 73, 1345-1352, 2009.

Bowman, R. A., Reeder, J. D., and Wienhold, B. J.: Quantifying laboratory and field variability to assess potential for carbon sequestration, Commun. Soil Sci. Plan., 33, 1629-1642, doi:10.1081/CSS-120004304, 2002.

Brenning, A., Koszinski, S., and Sommer, M.: Geostatistical homogenization of soil conductivity across field boundaries, Geoderma, 143, 254-260, doi:10.1016/j.geoderma.2007.11.007, 2008.

Bui, E. N., Henderson, B. L., and Viergever, K.: Knowledge discovery from models of soil properties developed through data mining, Ecol. Model., 191, 431-446, doi:10.1016/j.ecolmodel.2005.05.021, 2006.

Bushnell, T. M.: Some aspects of the soil catena concept, Soil Sci. Soc. Proc., 7, 466-476, 1943.

Cambardella, C. A., Moorman, T. B., Novak, J. M., Parkin, T. B., Karlen, D. L., Turco, R. F., and Konopka, A. E.: Field-scale variability of soil properties in central Iowa soils, Soil Sci. Soc. Am., 58, 1501-1511, doi:10.2136/sssaj1994.03615995005800050033x, 1994.

Carlson, T. N., Gilles, R. R., and Perry, E. M.: A method to make use of thermal infrared temperature and NDVI measurements to infer surface soil water content and fractional vegetation cover, Remote Sensing Reviews, 9, 161-173, doi:10.1080/02757259409532220, 1994.

Churchill, R. R.: Aspect-related differences in badlands slope morphology, Ann. Assoc. Am. Geogr., 71, 374-388, doi:10.1111/j.1467-8306.1981.tb01363.x, 1981.

Cuff, J. R. I.: Quantifying erosion-causing parameters in a New Zealand watershed, in: Soil Conservation, edited by: El-Swaify, S. A., Moldenhauer, W. C., and Lo, A., Soil Conservation Society of America, Ankeny, 99-112, 1985.

Daughtry, C. S. T.: Discriminating crop residues from soil by shortwave infrared reflectance, Agronomy J., 93, 125-131, doi:10.2134/agronj2001.931125x, 2001.

Day, A. D. and Intalap, S.: Some effects of soil moisture stress on the growth of wheat (Triticum aestivum L. em Thell), Agronomy J., 62, 27-29, doi:10.2134/agronj1970.00021962006200010009x, 1970.

European Commission: European Soil Database v2, European Soil Data Centre, available at: http://eusoils.jrc.ec.europa.eu, last access: 7 October 2014.

FAO/IIASA/ISRIC/ISSCAS/JRC: Harmonized World Soil Database (version 1.2), FAO, Rome, Italy and IIASA, Laxenburg, Austria, 2012. 
Frazier, B. E. and Lee, G. B.: Characteristics and classification of three Wisconsin Histosols, Soil Sci. Soc. Am. J., 35, 776-780, doi:10.2136/sssaj1971.03615995003500050040x, 1971.

Gates, F. C.: The bogs of northern lower Michigan, Ecol. Monogr., 12, 216-254, doi:10.2307/1943542, 1942.

GLCF: Global Land Cover Facility, University of Maryland, available at: http://glcf.umd.edu/data, last access: 19 February 2014.

Goidts, E., Van Wesemael, B., and Crucifix, M.: Magnitude and sources of uncertainties in soil organic carbon (SOC) stock assessments at various scales, Eur. J. Soil Sci., 60, 723-739, doi:10.1111/j.1365-2389.2009.01157.x, 2009.

Gomez, C., Viscarra Rossel, R. A., and McBratney, A. B.: Soil organic carbon prediction by hyperspectral remote sensing and field vis-NIR spectroscopy: An Australian case study, Geoderma, 146, 403-411, doi:10.1016/j.geoderma.2008.06.011, 2008.

Goodman, L. A.: On the exact variance of products, J. Am. Stat. Assoc., 55, 708-713, 1960.

Grace, J.: Understanding and managing the global carbon cycle, J. Ecology, 92, 189-202, doi:10.1111/j.0022-0477.2004.00874.x, 2004.

Grimm, R., Behrens, T., Märker, M., and Elsenbeer, H.: Soil organic carbon concentrations and stocks on Barro Colorado Island - digital soil mapping using random forests analysis, Geoderma, 146, 102-113, doi:10.1016/j.geoderma.2008.05.008, 2008.

Hatfield, J. L., Gitelson, A. A., Schepers, J. S., and Walthall, C. L.: Application of spectral remote sensing for agronomic decisions, Agronomy J., 100, S117-S131, doi:10.2134/agronj2006.0370c, 2008.

Heilman, J. L., Kanemasu, E. T., Rosenberg, N. J., and Blad, B. L.: Thermal scanner measurement of canopy temperatures to estimate evapotranspiration, Remote Sens. Environ., 5, 137-145, doi:10.1016/0034-4257(76)90044-4, 1976.

Holmes, G., Hall, M., and Frank, E.: Generating rule sets from model trees, Advanced Topics in Artificial Intelligence, Lecture Notes Comput. Sc., 1747, 1-12, doi:10.1007/3-540-46695-9_1, 1999.

Huete, A. R.: A soil-adjusted vegetation index (SAVI), Remote Sens. Environ., 25, 295-309, doi:10.1016/0034-4257(88)90106X, 1988.

Huggett, R. J.: Soil landscape systems: a model of soil genesis, Geoderma, 13, 1-22, doi:10.1016/0016-7061(75)90035-X, 1975.

Hunckler, R. V. and Schaetzl, R. J.: Spodosol development as affected by geomorphic aspect, Baraga County, Michigan, Soil Sci. Soc. Am. J., 61, 1105-1115, doi:10.2136/sssaj1997.03615995006100040017x, 1997.

Jobbágy, E. G. and Jackson, R. B.: The vertical distribution of soil organic carbon and its relation to climate and vegetation, Ecol. Appl., 10, 423-436, doi:10.1890/10510761(2000)010[0423:TVDOSO]2.0.CO;2, 2000.

Johnson, D. L., Keller, E. A., and Rockwell, T. K.: Dynamic pedogenesis: new views on some key concepts, and a model for interpreting quaternary soils, Quaternary Res., 33, 306-319, doi:10.1016/0033-5894(90)90058-S, 1990.

Johnston, A. E., Poulton, P. R., and Coleman, K.: Soil organic matter: its importance in sustainable agriculture and carbon dioxide fluxes, Adv. Agronomy, 101, 1-57, doi:10.1016/S00652113(08)00801-8, 2009.

Johnston, C. A., Groffman, P., Breshears, D. D., Cardon, Z. G., Currie, W., Emanuel, W., Gaudinski, J., Jackson, R. B., Lajtha, K.,
Nadelhoffer, K., Nelson Jr., D., Mac Post, W., Retallack, G., and Wielopolski, L.: Carbon cycling in soil, Front. Ecol. Environ., 2, 522-528, doi:10.2307/3868382, 2004.

Kay, B. D.: Soil structure and organic carbon: a review, in: Soil Processes and the Carbon Cycle, edited by: Lal, R., Kimble, J. M., Follett, R. F., and Stewart, B. A., CRC Press, Boca Raton, 169-197, 1998.

Kempen, B., Brus, D. J., and Stoorvogel, J. J.: Threedimensional mapping of soil organic matter content using soil type-specific depth functions, Geoderma, 162, 107-123, doi:10.1016/j.geoderma.2011.01.010, 2011.

Kennedy, B. A.: Valley-side slopes and climate, in: Geomorphology and Climate, edited by: Derbyshire, E., John Wiley, London, 171-201, 1976.

Khalil, M. I., Kiely, G., O’Brien, P., and Müller, C.: Organic carbon stocks in agricultural soils in Ireland using combined empirical and GIS approaches, Geoderma, 193-195, 222-235, doi:10.1016/j.geoderma.2012.10.005, 2013.

Königlich Preußische Geologische Landesanstalt: Geologische Karte von Preußen und benachbarten Bundesstaten, 1:25,000 (Geological Map of Prussia and adjacent Federal States, 1:25,000), Landesamt f. Geologie und Bergwesen, Halle, Sachsen-Anhalt, Germany, Sheet Wulfen 4137, 1913a.

Königlich Preußische Geologische Landesanstalt: Geologische Karte von Preußen und benachbarten Bundesstaten, 1:25,000 (Geological Map of Prussia and adjacent Federal States, 1:25,000), Landesamt f. Geologie und Bergwesen, Halle, Sachsen-Anhalt, Germany, Sheet Cöthen 4237, $1913 b$.

Krause, H. H., Rieger, S., and Wilde, S. A.: Soils and forest growth on different aspects in the Tanana watershed of interior Alaska, Ecology, 40, 492-495, doi:10.2307/1929773, 1959.

Kravchenko, A. N., Robertson, G. P., Hao, X., and Bullock, D. G.: Management practice effects on surface total carbon: differences in spatial variability patterns, Agronomy J., 98, 15591568, doi:10.2134/agronj2006.0066, 2006a.

Kravchenko, A. N., Robertson, G. P., Snap, S. S., and Smucker, A. J. M.: Using information about spatial variability to improve estimates of total soil carbon, Agronomy J., 98, 823-829, doi:10.2134/agronj2005.0305, 2006b.

$\mathrm{Ku}, \mathrm{H}$. H.: Notes on the use of propagation of error formulas, Journal of Research of the National Bureau of Standards - C. Engineering and Instrumentation, 70C, 263-273, 1966.

Kühn, J., Brenning, A., Wehrhan, M., Koszinski, S., and Sommer, M.: Interpretation of electrical conductivity patterns by soil properties and geological maps for precision agriculture, Precis. Agric., 10, 490-507, doi:10.1007/s11119-008-9103-z, 2009.

Lal, R.: Soil carbon sequestration impacts on global climate change and food security, Science, 304, 1623-1627, doi:10.1126/science.1097396, 2004.

Lacoste, M., Minasny, B., McBratney, A., Michot, D., Viaud, V., and Walter, C.: High resolution 3D mapping of soil organic carbon in a heterogeneous agricultural landscape, Geoderma, 213, 296-311, doi:10.1016/j.geoderma.2013.07.002, 2014.

Lemercier, B., Lacoste, M., Loum, M., and Walter, C.: Extrapolation at regional scale of local soil knowledge using boosted classification trees: a two-step approach, Geoderma, 171-172, 7584, doi:10.1016/j.geoderma.2011.03.010, 2012.

Li, Z. L., Tang, R., Wan, Z., Bi, Y., Zhou, C., Tang, B., Yan, G., and Zhang, X.: A review of current methodologies for regional evap- 
otranspiration estimation from remotely sensed data, Sensors, 9 , 3801-3853, doi:10.3390/s90503801, 2009.

Liebens, J. and VanMolle, M.: Influence of estimation procedure on soil organic carbon stock assessment in Flanders, Belgium, Soil Use Manage., 19, 364-371, doi:10.1111/j.14752743.2003.tb00327.x, 2003.

Lobell, D. B. and Asner, G. P.: Moisture effects on soil reflectance, Soil Sci. Soc. Am. J., 66, 722-727, doi:10.2136/sssaj2002.7220, 2002.

Lowther, J. R., Smethurst, P. J., Carlyle, J. C., and Nambiar, E. K. S.: Methods for determining organic carbon in podzolic sands, Commun. Soil Sci. Plan., 21, 457-470, doi:10.1080/00103629009368245, 1990.

Lufafa, A., Diédhiou, I., Samba, S. A. N., Séné, M., Khouma, M., Kizito, F., Dick, R. P., Dossa, E., and Noller, J. S.: Carbon stocks and patterns in native shrub communities of Senegal's Peanut Basin, Geoderma, 146, 75-82, doi:10.1016/j.geoderma.2008.05.024, 2008.

Malone, B. P., McBratney, A. B., and Minasny, B.: Empirical estimates of uncertainty for mapping continuous depth functions of soil attributes, Geoderma, 160, 614-626, doi:10.1016/j.geoderma.2010.11.013, 2011.

Mardia, K. V., Kent, J. T., and Bibby, J. M.: Multivariate Analysis, Academic Press, London, United Kingdom, 521 pp., 1979.

Martin, M. P., Orton, T. G., Lacarce, E., Meersmans, J., Saby, N. P. A., Paroissien, J. B., Jolivet, C., Boulonne, L., and Arrouays, D.: Evaluation of modelling approaches for predicting the spatial distribution of soil organic carbon stocks at the national scale, Geoderma, 223-225, 97-107, doi:10.1016/j.geoderma.2014.01.005, 2014.

Martin, M. P., Wattenbach, M., Smith, P., Meersmans, J., Jolivet, C., Boulonne, L., and Arrouays, D.: Spatial distribution of soil organic carbon stocks in France, Biogeosciences, 8, 1053-1065, doi:10.5194/bg-8-1053-2011, 2011.

McBratney, A. B. and Pringle, M. J.: Estimating average and proportional variograms of soil properties and their potential use in precision agriculture, Precis. Agric., 1, 125-152, doi:10.1023/A:1009995404447, 1999.

McDonald, E. V. and Busacca, A. J.: Record of pre-late Wisconsin giant floods in the Channeled Scabland interpreted from loess deposits, Geology, 16, 728-731, doi:10.1130/00917613(1988)016<0728:ROPLWG>2.3.CO;2, 1988.

Meersmans, J., Van Wesemael, B., De Ridder, F., Fallas Dotti, M., De Baets, S., and Van Molle, M.: Changes in organic carbon distribution with depth in agricultural soils in northern Belgium, 1960-2006, Global Change Biol., 15, 2739-2750, doi:10.1111/j.1365-2486.2009.01855.x, 2009.

Migdall, S., Bach, H., Bobert, J., Wehrhan, M., and Mauser, W.: Inversion of a canopy reflectance model using hyperspectral imagery for monitoring wheat growth and estimating yield, Precis. Agric., 10, 508-524, doi:10.1007/s11119-009-9104-6, 2009.

Miller, B. A., Koszinski, S., Wehrhan, M., and Sommer, M., Impact of multi-scale predictor selection for modeling soil properties, Geoderma, 239-240, 97-106, doi:10.1016/j.geoderma.2014.09.018, 2015.

Minasny, B. and McBratney, A. B.: Regression rules as a tool for predicting soil properties from infrared reflectance spectroscopy, Chemometr. Intell. Lab., 94, 72-79, doi:10.1016/j.chemolab.2008.06.003, 2008.
Minasny, B., McBratney, A. B., Malone, B. P., and Wheeler, I.: Digital mapping of soil carbon, Adv. Agron., 118, 1-47, doi:10.1016/B978-0-12-405942-9.00001-3, 2013.

Mishra, U., Lal, R., Liu, D., and Van Meirvenne, M.: Predicting the spatial variation of the soil organic carbon pool at a regional scale, Soil Sci. Soc. Am. J., 74, 906-914, doi:10.2136/sssaj2009.0158, 2010.

Moore, I. D., Grayson, R. B., and Ladson, A. R.: Digital terrain modelling: a review of hydrological, geomorphological, and biological applications, Hydrol. Process., 5, 3-30, doi:10.1002/hyp.3360050103, 1991.

Mulder, V. L., de Bruin, S., Schaepman, M. E., and Mayr, T. R.: The use of remote sensing in soil and terrain mapping - a review, Geoderma, 162, 1-19, doi:10.1016/j.geoderma.2010.12.018, 2011.

Myneni, R. B., Hall, F. G., Sellers, P. J., and Marshak, A. L.: The interpretation of spectral vegetation indexes, IEEE T. Geosci. Remote Sens., 33, 481-486, doi:10.1109/36.377948, 1995.

Neemann, W.: Bestimmung des Bodenerodierbarkeitsfaktors für winderosionsgefährdete Böden Norddeutschlands (Determination of soil erodibility factors for wind-erosion endangered soils in Northern Germany), Geologisches Jahrbuch Reihe F, 25, 131 pp., 1991.

Nyssen, J., Temesgen, H., Lemenih, M., Zenebe, A., Haregeweyn, N., and Haile, M.: Spatial and temporal variation of soil organic carbon stocks in a lake retreat area of the Ethiopian Rift Valley, Geoderma, 146, 261-268, doi:10.1016/j.geoderma.2008.06.007, 2008.

Orton, T. G., Pringle, M. J., Page, K. L., Dalal, R. C., and Bishop, T. F. A.: Spatial prediction of soil organic carbon stock using a linear model of coregionalisation, Geoderma, 230-231, 119130, doi:10.1016/j.geoderma.2014.04.016, 2014.

Panda, D. K., Singh, R., Kundu, D. K., Chakraborty, H., and Kumar, A.: Improved estimation of soil organic carbon storage uncertainty using first-order Taylor series approximation, Soil Sci. Soc. Am. J., 72, 1708-1710, doi:10.2136/sssaj2007.0242N, 2008.

Pennock, D. J. and De Jong, E.: The influence of slope curvature on soil erosion and deposition in hummock terrain, Soil Sci., 144, 209-217, doi:10.1097/00010694-198709000-00007, 1987.

Petropoulus, G., Carlson, T. N., Wooster, M. J., and Islam, S.: A review of Ts/VI remote sensing based methods for the retrieval of land surface energy fluxes and soil surface moisture, Prog. Phys. Geogr., 33, 224-250, doi:10.1177/0309133309338997, 2009.

Phachomphon, K., Dlamini, P., and Chaplot, V.: Estimating carbon stocks at a regional level using soil information and easily accessible auxiliary variables, Geoderma, 155, 372-380, doi:10.1016/j.geoderma.2009.12.020, 2010.

Phillips, J. D.: On the relations between complex systems and the factorial model of soil formation (with discussion), Geoderma, 86, 1-21, doi:10.1016/S0016-7061(98)00054-8, 1998.

Powlson, D. S., Whitmore, A. P., and Goulding, K. W. T.: Soil carbon sequestration to mitigate climate change: a critical reexamination to identify the true and the false, Eur. J. Soil Sci., 62, 42-55, doi:10.1111/j.1365-2389.2010.01342.x, 2011.

Quinlan, J. R.: Learning with continuous classes, Proceedings of the 5th Australian Joint Conference on Artificial Intelligence, 343348, 1992. 
Quinlan, J. R.: Combining instance-based and model-based learning, in: Proceedings of the Tenth International Conference on Machine Learning, edited by: Kaufmann, M., 236-243, 1993.

Quinlan, J. R.: C4.5: Programs for machine learning, Mach. Learn., 16, 235-240, 1994.

Rasmussen, M. S.: Developing simple, operational, consistent NDVI-vegetation models by applying environmental and climatic information: Part I. Assessment of net primary production, Int. J. Remote Sens., 19, 97-117, doi:10.1080/014311698216459, 1998.

Rawls, W. J., Brakensiek, D. L., and Saxton, K. E.: Estimation of soil water properties, Transactions of the American Society of Agricultural Engineers, 25, 1316-1320, 1982.

Rawls, W. J., Pachepsky, Y. A., Ritchie, J. C., Sobecki, T. M., and Bloodworth, H.: Effect of soil organic carbon on soil water retention, Geoderma, 116, 61-76, doi:10.1016/S00167061(03)00094-6, 2003.

Richards, J. A.: Remote Sensing Digital Image Analysis, Springer, 439 pp., 2006.

Richter, D. D. and Markewitz, D.: How deep is soil?, Bioscience, 45, 600-609, doi:10.2307/1312764, 1995.

Schaetzl, R. J.: Complete soil profile inversion by tree uprooting, Physical Geogr., 7, 181-189, doi:10.1080/02723646.1986.10642290, 1986.

Schaetzl, R. J.: Effects of treethrow microtopography on the characteristics and genesis of Spodosols, Michigan, USA, Catena, 17, 111-126, doi:10.1016/0341-8162(90)90002-U, 1990.

Schrumpf, M., Schulze, E. D., Kaiser, K., and Schumacher, J.: How accurately can soil organic carbon stocks and stock changes be quantified by soil inventories?, Biogeosciences, 8, 1193-1212, doi:10.5194/bg-8-1193-2011, 2011.

Schwartz, D. and Namri, M.: Mapping the total organic carbon in the soils of the Congo, Global Planet. Change, 33, 77-93, doi:10.1016/S0921-8181(02)00063-2, 2002.

Selige, S., Böhner, J., and Schmidhalter, U.: High resolution topsoil mapping using hyperspectral image and field data in multivariate regression modeling procedures, Geoderma, 136, 235-244, doi:10.1016/j.geoderma.2006.03.050, 2006.

Simbahan, G. C., Dobermann, A., Goovaerts, P., Ping, J., and Haddix, L.: Fine-resolution mapping of soil organic carbon based on multivariate secondary data, Geoderma, 132, 471-489, doi:10.1016/j.geoderma.2005.07.001, 2006.

Snyder, V. A. and Vazquez, M. A.: Structure, in: Encyclopedia of Soils in the Environment, edited by: Hillel, D., Hatfield, J. L., Powlson, D. S., Rozenweig, C., Scow, K. M., Singer, M. J., and Sparks, D. L., Elsevier Academic Press, 54-68, 2005.

Shrestha, D. L. and Solomatine, D. P.: Machine learning approaches for estimation of prediction interval for the model output, Neural Networks, 19, 225-235, doi:10.1016/j.neunet.2006.01.012, 2006.

Sombroek, W. G., Fearnside, P. M., and Cravo, M.: Geographic assessment of carbon stored in Amazonian terrestrial ecosystems and their soils in particular, in: Global Climate Change and Tropical Ecosystems, edited by: Lal, R., Kimble, J. M., and Stewart, B. A., CRC Lewis, Boca Raton, 375-389, 2000.
Sommer, M., Halm, D., Weller, U., Zarei, M., and Stahr, K.: Lateral podzolization in a granite landscape, Soil Sci. Soc. Am. J., 64, 1434-1442, doi:10.2136/sssaj2000.6441434x, 2000.

Sommer, M., Gerke, H. H., and Deumlich, D.: Modelling soil landscape genesis - a "time split" approach for hummocky agricultural landscapes, Geoderma, 145, 480-493, doi:10.1016/j.geoderma.2008.01.012, 2008.

Soon, Y. K. and Abboud, S.: A comparison of some methods for soil organic carbon determination, Commun. Soil Sci. Plan., 22, 943-954, doi:10.1080/00103629109368465, 1991.

Stevens, A., Udelhoven, T., Denis, A., Tychon, B., Lioy, R., Hoffmann, L., and van Wesemael, B.: Measuring soil organic carbon in croplands at regional scale using airborne imaging spectroscopy, Geoderma, 158, 32-45, doi:10.1016/j.geoderma.2009.11.032, 2010.

Sutherland, R. A.: Loss-on-ignition estimates of organic matter and relationships to organic carbon in fluvial sediments, Hydrobiologia, 389, 153-167, doi:10.1023/A:1003570219018, 1998.

Taylor, J. R.: An Introduction to Error Analysis: The Study of Uncertainties in Physical Measurements, 2nd Edn., University Science Books, Sausalito, California, USA, 1997.

Ungaro, F., Staffilani, F., and Tarocco, P.: Assessing and mapping topsoil organic carbon stock at regional scale: a scorpan kriging approach conditional on soil map delineations and land use, Land Degrad. Dev., 21, 565-581, doi:10.1002/ldr.998, 2010.

USGS: Earth Explorer, US Geological Survey, available at: http: //earthexplorer.usgs.gov, last access: 19 February 2014.

van Breda Weaver, A.: The distribution of soil erosion as a function of slope aspect and parent material in Ciskei, Southern Africa, GeoJournal, 23, 29-34, doi:10.1007/BF00204406, 1991.

Walter, C., Viscarra Rossel, R. A., and McBratney, A. B.: Spatiotemporal simulation of the field-scale evolution of organic carbon over the landscape, Soil Sci. Soc. Am. J., 67, 1477-1486, doi:10.2136/sssaj2003.1477, 2003.

Weisstein, E. W.: Error Propagation, Wolfram MathWorld, available at: http://mathworld.wolfram.com/ErrorPropagation.html, last access: 25 August 2014.

Wilhelm, W. W., Johnson, J. M. F., Hatfield, J. L., Voorhees, W. B., and Linden, D. R.: Crop and soil productivity response to corn residue removal: a literature review, Agronomy J., 96, 117, 2004.

Wilson, J. P. and Gallant, J. C. (Eds.): Terrain Analysis: Principles and Applications, John Wiley \& Sons, 2000.

Xie, Y., Sha, Z., and Yu, M.: Remote sensing imagery in vegetation mapping: a review, J. Plant Ecol., 1, 9-23, doi:10.1093/jpe/rtm005, 2008.

Zevenbergen, L. W. and Thorne, C. R.: Quantitative analysis of land surface topography, Earth Surf. Proc. Land., 12, 47-56, doi:10.1002/esp.3290120107, 1987.

Zhang, Z., Yu, D., Shi, X., Warner, E., Ren, H., Sun, W., Tan, M., and Wang, H.: Application of categorical information in the spatial prediction of soil organic carbon in the red soil area of China, Soil Sci. Plant Nutr., 56, 307-318, doi:10.1111/j.17470765.2010.00457.x, 2010. 